\title{
Improvement of aerosol optical depth retrieval from MODIS spectral reflectance over the global ocean using new aerosol models archived from AERONET inversion data and tri-axial ellipsoidal dust database
}

\author{
J. Lee ${ }^{1,2,3}$, J. Kim ${ }^{1,4}$, P. Yang ${ }^{5}$, and N. C. Hsu ${ }^{3}$ \\ ${ }^{1}$ Institute of Earth, Astronomy, and Atmosphere, Brain Korea 21 Program, Department of Atmospheric Sciences, \\ Yonsei University, Seoul, Republic of Korea \\ ${ }^{2}$ Earth System Science Interdisciplinary Center, University of Maryland College Park, College Park, MD, USA \\ ${ }^{3}$ NASA Goddard Space Flight Center, Greenbelt, MD, USA \\ ${ }^{4}$ Joint Institute for Regional Earth System Science and Engineering, University of California Los Angeles, \\ Los Angeles, CA, USA \\ ${ }^{5}$ Department of Atmospheric Sciences, Texas A\&M University, College Station, TX, USA
}

Correspondence to: J. Kim (jkim2@yonsei.ac.kr)

Received: 5 September 2011 - Published in Atmos. Chem. Phys. Discuss.: 19 December 2011

Revised: 27 June 2012 - Accepted: 29 June 2012 - Published: 6 August 2012

\begin{abstract}
New over-ocean aerosol models are developed by integrating the inversion data from the Aerosol Robotic Network (AERONET) sun/sky radiometers with a database for the optical properties of tri-axial ellipsoid particles. The new aerosol models allow more accurate retrieval of aerosol optical depth (AOD) from the Moderate Resolution Imaging Spectroradiometer (MODIS) in the case of high AOD $(\mathrm{AOD}>0.3)$. The aerosol models are categorized by using the fine-mode fraction (FMF) at $550 \mathrm{~nm}$ and the singlescattering albedo (SSA) at $440 \mathrm{~nm}$ from the AERONET inversion data to include a variety of aerosol types found around the globe. For each aerosol model, the changes in the aerosol optical properties (AOPs) as functions of AOD are considered to better represent aerosol characteristics. Comparisons of AODs between AERONET and MODIS for the period from 2003 to 2010 show that the use of the new aerosol models enhances the AOD accuracy with a Pearson coefficient of 0.93 and a regression slope of 0.99 compared to 0.92 and 0.85 calculated using the MODIS Collection 5 data. Moreover, the percentage of data within an expected error of $\pm(0.03+0.05 \times \mathrm{AOD})$ is increased from $62 \%$ to $64 \%$ for overall data and from $39 \%$ to $51 \%$ for AOD $>0.3$. Errors in the retrieved AOD are further characterized with respect to the Ångström exponent (AE), scattering angle $(\Theta)$,
\end{abstract}

SSA, and air mass factor (AMF). Due to more realistic AOPs assumptions, the new algorithm generally reduces systematic errors in the retrieved AODs compared with the current operational algorithm. In particular, the underestimation of fine-dominated AOD and the scattering angle dependence of dust-dominated AOD are significantly mitigated as results of the new algorithm's improved treatment of aerosol size distribution and dust particle nonsphericity.

\section{Introduction}

Aerosols exert a significant impact on climate change and air quality. The small airborne particles regulate the radiation budget through both direct and indirect effects (IPCC, 2007), specifically, by scattering and absorbing radiation and by modifying cloud microphysics. Aerosols are known to affect human health by causing and worsening respiratory illnesses (Pope and Dockery, 2006). Because the spatio-temporal distribution of aerosols is highly variable, satellite observations have been extensively utilized to quantify aerosol optical properties (AOPs) over wide areas and with fine spatiotemporal resolution. 
Traditional 5-channel meteorological imagers, including single visible-band instruments aboard geostationary satellites, are used to continuously monitor aerosol optical depth (AOD), but have a limited ability to retrieve other parameters (Knapp et al., 2002; Wang et al., 2003; Kim et al., 2008). In contrast, multi-spectral instruments on board low Earth orbit (LEO) satellites, such as the Advanced Very High Resolution Radiometer (AVHRR), Sea-viewing Wide Field-of-view Sensor (SeaWiFS), and Moderate Resolution Imaging Spectroradiometer (MODIS), can retrieve aerosol size information and absorptivity (Higurashi and Nakajima, 1999, 2002; Mishchenko et al., 1999; Hsu et al., 2004, 2006; Remer et al., 2005; Kim et al., 2007; Levy et al., 2007b). The Geostationary Ocean Color Imager (GOCI), which observes spectral radiances centered at 412, 443, 490, 555, 660, 680, 745, and $865 \mathrm{~nm}$ from a geostationary orbit, has been used for hourly monitoring of AOD and to retrieve the fine-mode fraction (FMF) and aerosol types over East Asia (Lee et al., 2010b).

With their wide spatial and spectral coverage, the observations made by the MODIS instruments aboard the Terra and Aqua satellites provide an unprecedented opportunity to infer AOPs. MODIS has 36 spectral bands ranging from 0.41 to $15 \mu \mathrm{m}$ with three different spatial resolutions $(250 \mathrm{~m}$, $500 \mathrm{~m}, 1 \mathrm{~km}$ ) and with $2300 \mathrm{~km}$-wide swath coverage. Since the launches of MODIS in 1999 for Terra and 2002 for Aqua, numerous efforts have been made to retrieve, evaluate, and improve the aerosol products obtained. The original operational algorithms for dark vegetated areas (Kaufman et al., 1997) and oceans (Tanré et al., 1997) are two very important additions. The MODIS algorithms have been frequently updated to improve the quality of retrieved data by modifying cloud-masking processes, aerosol models, and the surface reflectance database (Remer et al., 2005; Levy et al., 2007a, b). Hsu et al. (2006) developed Deep-Blue algorithm, which is applicable to bright land surfaces including desert areas, to facilitate monitoring of dust aerosols over source regions. Consequently, the current MODIS operational algorithms provide the columnar aerosol amount (AOD) and size information (FMF, Ångström exponent [AE]) for full coverage of the Earth except for cloud- and snow-covered areas. In addition, the Deep-Blue algorithm also has the ability to retrieve the single-scattering albedo (SSA) of dust aerosols.

MODIS aerosol products have been validated extensively to evaluate data quality. Preliminary comparisons of AOD from Terra-MODIS with that observed from Aerosol Robotic Network (AERONET) Sun/sky radiometers (Holben et al., 1998) showed that the AOD at $660 \mathrm{~nm}$ over the ocean differed by only $2 \%$ on average, with negligible offset (Remer et al., 2002), while the Terra-MODIS AOD over land was underestimated by about $14 \%$ except for coastal areas (Chu et al., 2002). However, the comparison results for land varied significantly with location, partially due to different surface conditions and aerosol sources. On the contrary, a validation by Remer et al. (2008) showed an almost perfect regression slope for the AOD at $550 \mathrm{~nm}$ over land as calcu- lated by AERONET and MODIS, but an underestimation of AOD over the ocean from Aqua-MODIS, in particular for high AODs. It should be noted that the land algorithm has been modified substantially to resolve better aerosol models and surface reflectance (Levy et al., 2007a, b), whereas no substantial update has been made to the original ocean algorithm (Remer et al., 2005, 2006). Therefore, the significant improvement in the regression slope over land is likely attributed to improved aerosol models to some extent, because the slope largely depends on data in the high AOD regime where the aerosol signal dominates the surface signal.

In this paper, new aerosol models are introduced by integrating AERONET inversion data (Dubovik and King, 2000; Dubovik et al., 2006) with single-scattering property data from a tri-axial ellipsoid database (Meng et al., 2010). The AOPs of each aerosol model are used to calculate a lookup table (LUT) for spectral reflectances from MODIS. By using the LUT, retrieval and validation of AODs are performed over the global ocean using Aqua-MODIS data to improve the underestimation of AOD reported by Remer et al. (2008). The validation results are compared with those from the current operational algorithm to further characterize the effects of the new aerosol models.

\section{MODIS ocean algorithms}

Remer et al. $(2005,2006)$ described the current MODIS Collection 5 operational over-ocean algorithm (hereafter, C005 algorithm) in detail. The algorithm retrieves spectral AOD and FMF using spectral reflectances centered at 555, 650, $860,1240,1630$, and $2120 \mathrm{~nm}$ by comparing observed and pre-calculated reflectances. To this end, sophisticated forward radiative transfer simulations of the reflectances (i.e. LUT) need to be performed for various aerosol models, surface reflectances, and sun/satellite geometries. Because the top-of-atmosphere (TOA) reflectance consists of signals from both the surface and atmosphere, the algorithm specifies surface reflectance in terms of the Fresnel reflection accounting for sea-surface roughness with a wind speed of $6 \mathrm{~m} \mathrm{~s}^{-1}$ and zero water-leaving radiance except at $550 \mathrm{~nm}$ where a water-leaving radiance of 0.005 is assumed. The atmospheric contribution, aerosols in particular, is calculated using four fine-mode and five coarse-mode aerosols. Then, both spectral AOD and FMF $(550 \mathrm{~nm})$, a ratio of fine-mode AOD to total AOD, are simultaneously retrieved by minimizing the error between the observed and calculated reflectances for each of the 20 combinations from the fine- and coarse-mode aerosol models with the fixed AOD retrieved from $860 \mathrm{~nm}$.

A schematic flowchart of the C005 algorithm and a test algorithm to evaluate the effects of the new aerosol models introduced in this paper is provided in Fig. 1. The test algorithm is designed to use the same spectral reflectances as the C005 algorithm in order to constrain other effects that 


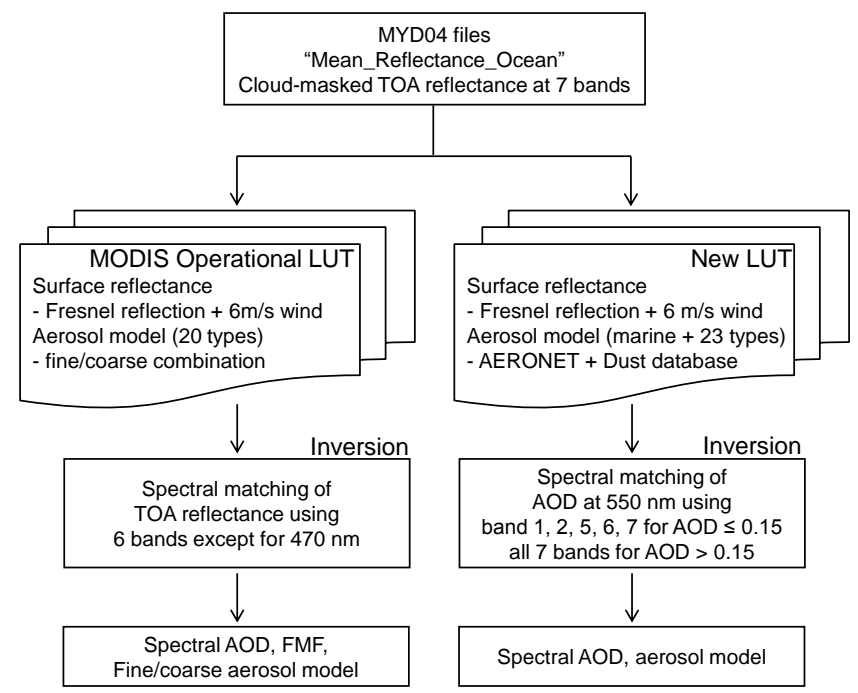

Fig. 1. Schematic flowchart of aerosol retrieval by the MODIS C005 algorithm (left column) and the test algorithm (right column). The test algorithm was designed to use the same observation data ("Mean_Reflectance_Ocean" in "MYD04" files) as the C005 algorithm to evaluate the effects of the new aerosol models only. The major difference between the two algorithms is the aerosol models used to calculate the LUT.

can arise from different pre-processing of the data. We used the "Mean_Reflectance_Ocean" product in the "MYD04" files, which provides cloud- and sediment-masked mean reflectance in $20 \times 20$ pixels of $500 \mathrm{~m}$ pixel-resolution data at seven wavelengths centered at $470,555,650,860,1240$, 1630 , and $2120 \mathrm{~nm}$. The product is the same as that used in the $\mathrm{C} 005$ algorithm. The major difference between the two algorithms is the aerosol model, and minor change is made to the inversion procedure. The test algorithm first retrieves AOD at $550 \mathrm{~nm}$ using every wavelength and aerosol model, and then selects the aerosol model that minimizes the standard deviation of the seven different AODs retrieved from each wavelength. The final AOD is chosen according to the selected aerosol model. By doing so, each wavelength can contribute equally to selecting the aerosol model, whereas $860 \mathrm{~nm}$ band has strong weighting in the $\mathrm{C} 005$ algorithm due to the calculation of spectral fitting error between observedand simulated-reflectances with a perfect match at $860 \mathrm{~nm}$ in selecting an aerosol model. In addition, for the low AOD case $(\mathrm{AOD} \leq 0.15)$, the test algorithm uses marine aerosol models and longer wavelengths $(650,860,1240,1630,2120 \mathrm{~nm})$ at which the water-body absorption is strong, whereas the algorithm uses full suite of aerosol models to be described in Sect. 3 and all the seven bands for AOD $>0.15$. This procedure is done by first retrieving AOD using the marine aerosol models and the longer wavelengths over the whole areas and then retrieving again using the full suite of aerosol models and all the wavelengths over the high AOD area determined by the former procedure. The purpose of using differ- ent wavelength sets for the different aerosol loadings is to reduce surface contribution to selecting an aerosol model particularly for low AOD condition, and to use blue-wavelength which contains relatively high surface signal but also sensitivity to aerosol absorption for high AOD condition. Therefore, reflectance criterion instead of AOD can also be used to discriminate aerosol-signal-abundant condition. However, marine aerosol assumption for $\mathrm{AOD} \leq 0.15$ ties us to use AOD criterion even though there could be errors in discriminating high aerosol loading by the retrieved results. As a result, the algorithm simultaneously retrieves AOD and an aerosol model, i.e. FMF and SSA since the aerosol models are categorized by using these two parameters. Note that no combination between aerosol models is assumed in the test algorithm in contrast to the MODIS operational algorithm.

\section{New aerosol models}

Use of a radiative transfer model (RTM) to simulate satelliteobserved TOA reflectance requires aerosol characteristics such as spectral refractive indices, size distribution, and nonsphericity to describe nonspherical particles. Otherwise, the spectral AOD, SSA, and phase function, which are derived from the aforementioned aerosol properties, are required. Thus, long-term AERONET inversion data that provides the AOPs for the globe can be used to simulate the satellite signal for various aerosol types. It should be noted that the AERONET observes ambient-columnar properties similar to those obtained from satellite observations, while insitu measurements provide near-ground properties. Moreover, the AERONET-retrieved AOPs represent the radiation field well for a wide scattering angle range, because the inversion data are retrieved to match the calculated radiation field with the observed sky radiances from the combined principal/almucantar planes (Dubovik and King, 2000; Dubovik et al., 2006). The inversion data provide AOPs at $440,675,870$, and $1020 \mathrm{~nm}$, but for MODIS observations, the tri-axial ellipsoid database, introduced in the work of Meng et al. (2010), is required to expand the wavelength range up to $2120 \mathrm{~nm}$.

\subsection{AERONET inversion data}

The quality-assured, "Level 2 Inversion All Points" data are used to derive aerosol models over the ocean for the test algorithm. To this end, data needs to be collected from specific AERONET stations chosen by distance from the ocean. The distance from the ocean is calculated by using geo-location information for each AERONET site and a high-resolution digital elevation model (DEM). The criterion for selecting the coastal stations was the distance within $7 \mathrm{~km}$ from the ocean. Figure 2 shows the 81 selected stations and the number of inversion data available to date. Although large portions of the data are from the US and Europe, where anthropogenic aerosols are dominant, the AERONET data in 


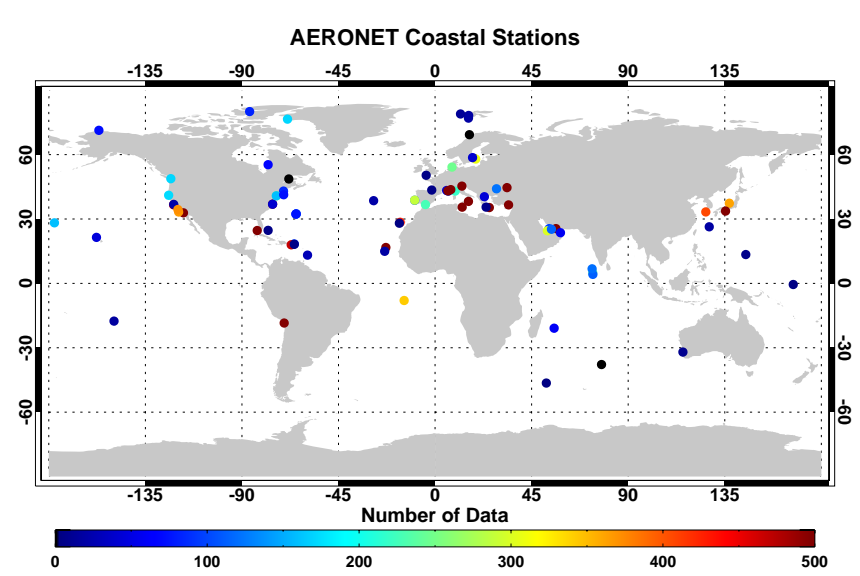

Fig. 2. Global distribution of AERONET sun/sky radiometers located in coastal areas (81 stations) used to archive aerosol optical properties for the test algorithm. The colors represent the number of inversion data points at each site. AERONET stations within $7 \mathrm{~km}$ from the ocean were chosen as coastal stations.

the downwind of North Africa are expected to provide AOPs of transported dust and biomass-burning aerosols. The data also cover dust aerosols transported from the Arabian Desert, both anthropogenic and dust aerosols over East Asia, and marine aerosols over the remote ocean. However, only one site is located downwind of Southern Africa and a lack of data may lead to uncertainties in the AOPs of biomass-burning aerosols from the area.

Aerosol models incorporated into satellite algorithms should account for the various aerosol types that exist and cause differences in the radiation field in order for the appropriate aerosol models to be selected from the observed radiation field. Therefore, use of size and absorptivity to classify aerosol types is the most reasonable method for remote sensing applications, because the two parameters directly affect the radiation field (Dubovik et al., 2002; Levy et al., 2007a; Mielonen et al., 2009; Lee et al., 2010a). While MODIS operational algorithms adopt fine- and coarse-mode aerosols separately and combine their signals during retrieval, the test algorithm adopts independent mixture-type models by classifying aerosol types from the AERONET explicitly with respect to the FMF $(550 \mathrm{~nm})$ and the SSA (440 nm) (Lee et al., 2010b).

Figure 3 shows the number of aerosol events with specific FMF and SSA values observed by AERONET throughout the globe and in coastal areas. The global data infers that aerosols from different locations have a wide range of FMF and SSA values, indicating the presence of various aerosol types with small to large particles and both absorbing and non-absorbing. For FMF less than 0.4 (coarsemode dominance), the SSA generally ranges from 0.85 to 0.95 , indicating absorption of blue-wavelengths by the coarse particle-dominated aerosols. Because Level 2 inversion data provides SSA for AOD $(440 \mathrm{~nm})>0.4$, the coarse particle-dominated aerosols mainly represent dust events. Note that sea salt, non-absorbing coarse-mode aerosols, generally occurs with low AOD values. For fine particledominated aerosols (FMF > 0.6), the range of values for SSA is wider than that for coarse particle-dominated aerosols. The high SSA values correspond to non-absorbing anthropogenic aerosols, such as sulfates and nitrates; whereas, the low SSA values imply the presence of black carbon (BC) (Hess et al., 1998; Wang and Martin, 2007). The major difference between global and coastal data is highlighted by the lack of data in the extremely low SSA regime. The high relative humidity $(\mathrm{RH})$ in coastal areas, the aging of $\mathrm{BC}$ during transport, and the few AERONET stations in downwind of biomass-burning aerosols may cause the result. Both high $\mathrm{RH}$ and $\mathrm{BC}$ aging are known to increase SSA (Wang and Martin, 2007).

Based on the representation of aerosol types classified using FMF and SSA (Lee et al., 2010a), aerosol models are created by quantized square-bins over the FMF and SSA domains. Binning intervals of 0.1 and 0.05 are used for FMF and SSA, respectively. Each aerosol model is further categorized as a function of AOD by averaging AOPs between foreand aft-medians of each AOD nodal point. If no data exist for a higher AOD bin, the AOPs of the previous bin is used. Consequently, the spectral AOD, SSA, and phase function are averaged over the three-dimensional domains of FMF, SSA, and AOD to be used as input data for the LUT calculations. Prior to the averaging, spectral AOD is normalized by itself at $550 \mathrm{~nm}$ and multiplied by each AOD nodal point. This method, however, has limited application to low AOD data, because SSA is retrieved only for AOD $(440 \mathrm{~nm})>0.4$. As an alternative, the SSA is assumed to be 0.99 , regardless of the wavelength, by considering the sea salt dominance in the low AOD regime over the ocean, while the other parameters (spectral AOD, phase function) are compiled from AERONET inversion data. For marine aerosol models used for $\mathrm{AOD} \leq 0.15$, only FMF criteria and AOD $<0.15$ are used to calculate the AOPs, and SSA is assumed to be 0.99. As a result, a total of 23 aerosol models for AOD $>0.15$ and 9 marine aerosol models for AOD $\leq 0.15$ are created with the number of data points constrained to be greater than 10 for each aerosol model. The aerosol models cover FMF ranging from 0.2 to 1.0 for $0.85<\mathrm{SSA}<0.95$ (16 types), from 0.3 to 1.0 for SSA $>0.95$ (7 types), and from 0.1 to 1.0 (9 types) for marine aerosol models. Dimensions of the LUT are summarized in Table 1. Note that simple extrapolation is used to retrieve AOD of severe dust storms or smoke events with AOD higher than 3.6 (LUT limit).

\subsection{Tri-axial ellipsoid database}

The AERONET inversion data provide AOPs for wavelengths ranging from 440 to $1020 \mathrm{~nm}$, while the MODIS observations cover the wavelengths from 470 to $2120 \mathrm{~nm}$. To expand the wavelength range of AERONET AOPs, data 

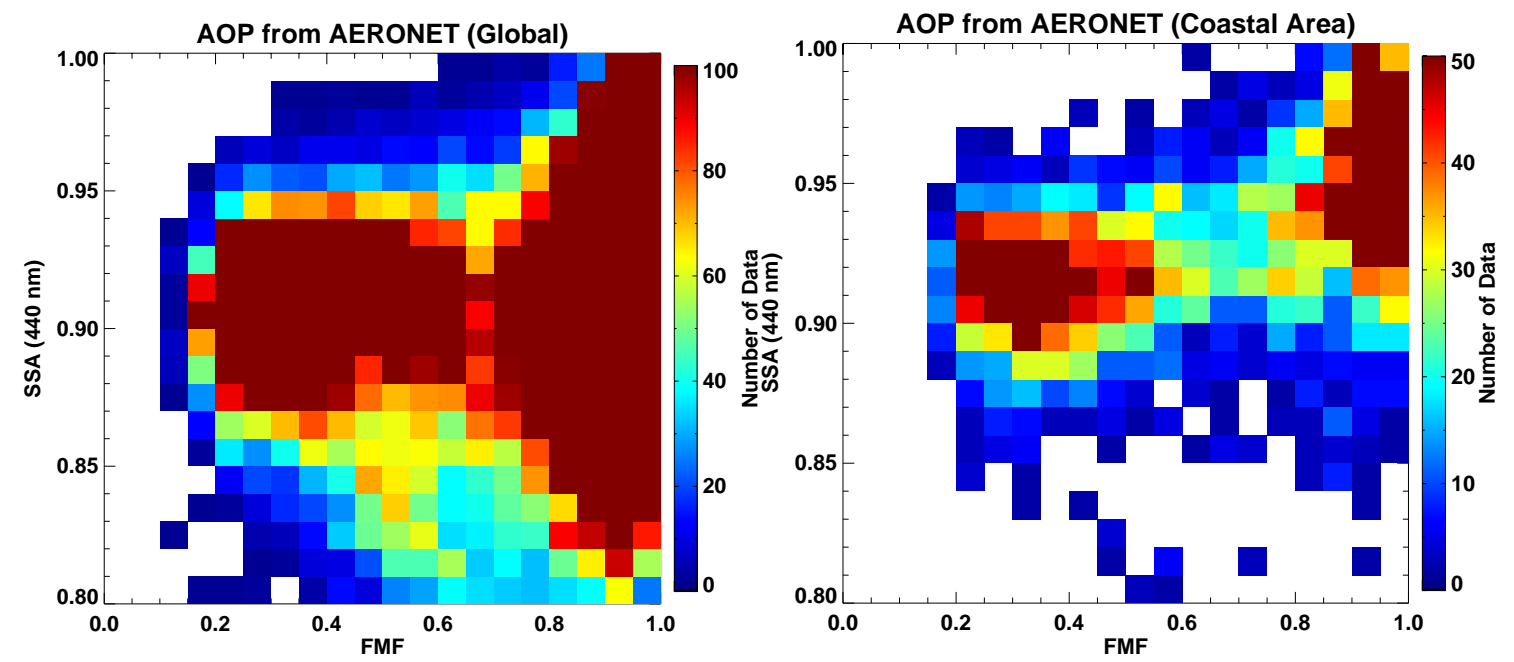

Fig. 3. The number of data points included in each FMF $(550 \mathrm{~nm})$ and SSA $(440 \mathrm{~nm})$ bin, archived from the AERONET inversion data over the globe (left) and coastal areas (right). The data were sorted into intervals of 0.05 and 0.01 for FMF and SSA, respectively. The AERONET stations in the coastal area are shown in Fig. 2.

Table 1. LUT dimensions for the MODIS over-ocean algorithm.

\begin{tabular}{|c|c|c|}
\hline Variable Name & $\begin{array}{l}\text { No. of } \\
\text { Entries }\end{array}$ & Entries \\
\hline Wavelength $(\lambda)$ & 7 & $\begin{array}{l}470,555,650,860,1240, \\
1630,2120 \mathrm{~nm} \\
\text { (band } 3,4,1,2,5,6,7, \\
\text { respectively) }\end{array}$ \\
\hline $\operatorname{SZA}\left(\theta_{\mathrm{O}}\right)$ & 8 & $0,10, \ldots, 70^{\circ}$ \\
\hline $\operatorname{SAZA}\left(\theta_{\mathrm{S}}\right)$ & 8 & $0,10, \ldots, 70^{\circ}$ \\
\hline RAA $(\phi)$ & 19 & $0,10, \ldots, 180^{\circ}$ \\
\hline $\operatorname{AOD}(\tau)$ & 9 & $\begin{array}{l}0.0,0.1,0.3,0.6,1.0,1.5, \\
2.1,2.8,3.6\end{array}$ \\
\hline Aerosol Model & 23 & $\begin{array}{l}\text { Classified by FMF and SSA } \\
\text { from AERONET inversion } \\
\text { data }\end{array}$ \\
\hline
\end{tabular}

SZA: solar zenith angle, SAZA: satellite zenith angle, RAA: relative azimuth angle.

from the tri-axial ellipsoid database (Meng et al., 2010) are used in this study. The database containing the singlescattering properties of individual tri-axial ellipsoidal particles was computed using the Lorentz-Mie code (Bohren and Huffman, 1983), the T-matrix code (Mishchenko and Travis, 1998), the Amsterdam discrete dipole approximation (DDA) code (Yurkin and Hoekstra, 2009), and the improved geometric optics method (IGOM) code (Yang and Liou, 1996; Yang et al., 2007; Bi et al., 2009). Because tri-axial ellipsoidal shapes include spheres and ellipsoids with a number of aspect ratios, the application of the database can be expanded to non-dust aerosols. The database provides extinction efficiency, SSA, phase matrix, etc., for various refractive indices, size parameters, and aspect ratios, thus the proxy of the AERONET AOPs (spectral AOD, SSA, and phase function) can be extracted when given the spectral refractive indices, size distribution, aspect ratios, and nonsphericity.

The procedure to calculate the AOPs of the predefined aerosol models at the longer wavelengths $(\lambda \geq 1240 \mathrm{~nm})$ is summarized as follows.

1. Extracting extinction efficiency, SSA, and phase function for individual spherical/nonspherical particles from the database by inputting refractive indices, size parameter, and aspect ratios. Note that the RTM we used requires spectral AOD, SSA, and phase function to calculate TOA reflectances. The refractive indices for each aerosol model are from the MODIS operational algorithm since AERONET inversion data does not provide the values at the longer wavelengths.

2. Integrating the AOPs of individual particles using predefined size distributions by assuming spherical particles. The size distribution of each aerosol model is calculated by averaging AERONET inversion data the same as AOPs for the shorter wavelengths.

3. Doing the same procedure as (2) for pure nonspherical particles. Thus, integrating the AOPs of individual particles in both size distribution and aspect ratio distribution space. The same aspect ratio distribution as AERONET inversion algorithm is used for consistency with the AOPs calculated for the shorter wavelengths.

4. Calculating weighting mean of the AOPs for pure spheres and pure nonspherical particles using \%sphericity. The mean values of \%sphericity of each aerosol model are calculated by averaging AERONET inversion data. 


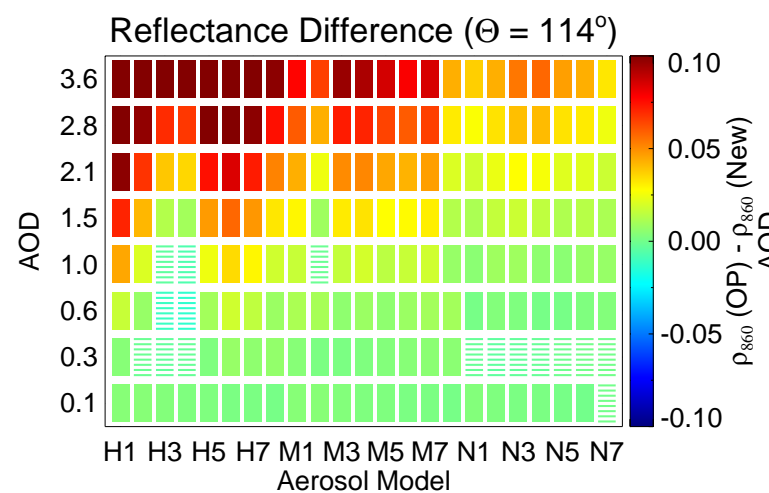

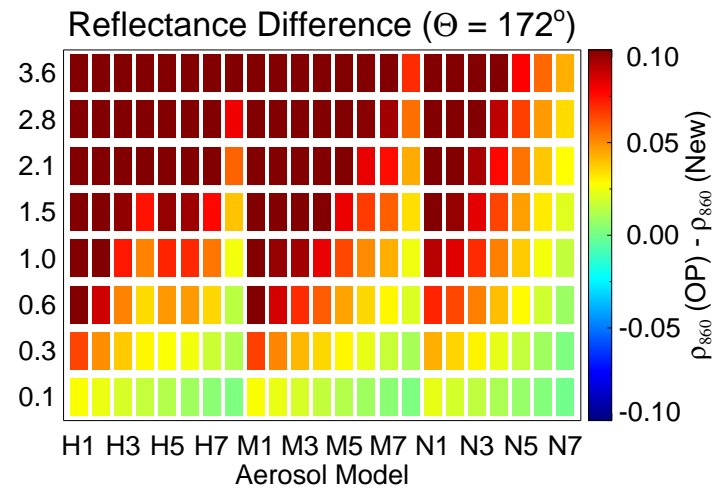

Fig. 4. TOA reflectance difference at $860 \mathrm{~nm}$ between MODIS aerosol models and new aerosol models with respect to AOD for a given geometry. SZA $\left(\theta_{\mathrm{O}}\right)$ and SAZA $\left(\theta_{\mathrm{S}}\right)$ are assumed to be $50^{\circ}$ for both tests and RAA $(\phi)$ is assumed to be $90^{\circ}$ (left) and $170^{\circ}$ (right), resulting in scattering angle $(\Theta)$ of $114^{\circ}$ and $172^{\circ}$, respectively. Corresponding MODIS aerosol models to the new aerosol models are created by combining F2 ("Water Soluble") and C8 ("Dust-like type") aerosol models from Remer et al. (2006) for SSA < 0.95 and F4 ("Water Solublt with humidity") and C8 for SSA > 0.95 using FMF values from new aerosol models. Negative values are shown in line-fill.

More specifically, the refractive indices of "water soluble" and "water soluble with humidity" from the C005 aerosol models (Remer et al., 2006) are used for fine-mode $(0.85<\mathrm{SSA}<0.95$ and SSA $>0.95$, respectively), and the refractive indices of "dust-like type" and "wet sea salt type" are used for coarse-mode (AOD $>0.1$ and $\mathrm{AOD}=0.1$, respectively). Although the refractive indices of the MODIS aerosol models are not completely consistent with those of the new aerosol models, the low sensitivity of satellite signals to the fine-mode aerosols at longer wavelengths ( $\geq 1240 \mathrm{~nm}$ ) due to their low AOD (high AE) and the relatively wellknown absorption properties of dust (almost non-absorbing) (Hsu et al., 2004; Remer et al., 2005) are expected to result in smaller errors compared to excluding the longer wavelengths in the retrieval algorithm. A test retrieval using only shorter wavelengths (not shown for brevity) showed that exclusion of the longer wavelengths resulted in larger uncertainties than its counterpart particularly for determining aerosol size information. Nonetheless, more accurate optical property information for the longer wavelengths is still desirable for further improvement in the aerosol models and thus retrieval results.

With regard to nonsphericity and aspect ratios, mean "\% sphericity" from the AERONET data and fixed spheroid mixture distribution are used as described in Dubovik et al. (2006). The dataset compiled by combining the AERONET inversion data and tri-axial ellipsoid database data is used as input data into RTM calculations. The optical properties of the 23 aerosol models are summarized in Table 2. To calculate the LUT, a discrete ordinate radiative transfer (DISORT) code implemented into the libRadtran software package (Mayer and Kylling, 2005) is used. Due to the advantage of directly inputting the phase function into the libRadtran package, nonsphericity, which mainly affects phase function, can be readily handled with the software. However, the polarization effect is not included the same as in the $\mathrm{C} 005$ algorithm.

\section{Sensitivity study}

The possible differences in retrieved AOD between the C005 algorithm and test algorithm are analysed before applying the developed algorithm to actual TOA reflectance data. Figure 4 shows the difference in the calculated TOA reflectance values between the $\mathrm{C} 005$ aerosol models and the new aerosol models for different AOD values at $860 \mathrm{~nm}$, the reference wavelength used in selecting aerosol models from the C005 algorithm. The other wavelengths show similar tendencies. The corresponding $\mathrm{C} 005$ aerosol models to the new aerosol models are created by combining the F2 ("water soluble") and C8 ("dust-like type") aerosol models in Remer et al. (2006) for SSA $<0.95$ and the F4 ("water solublt with humidity") and C8 for SSA $>0.95$ by using FMF values from the new aerosol models. The results generally show that the C005 aerosol models overestimate the TOA reflectance, i.e., underestimation of AOD with a given TOA reflectance, compared to the new aerosol models, and the overestimation tends to increase with AOD and absorptivity. The increasing overestimation with AOD is mainly due to the increasing particle size with AOD from the new aerosol models. Increasing particle size results in decreasing TOA reflectance due to a decrease in the back-scattering fraction of reflected radiation. Only slight underestimations are found in the dust-dominated models (H2, H3, H4, M2) and in the non-absorbing models (N1 through N7) in the side-scattering case for low AOD. On the other hand, consistent overestimation is present in the back-scattering direction, indicating difference in phase function between spherical and nonspherical particles. The phase function of spherical particle has lower values at sidescattering angles and higher values at back-scattering angles compared to their nonspherical counterparts. The underestimation from the $\mathrm{C} 005$ aerosol model for non-absorbing fine-mode (N5 through N7) for low AOD is partially due to larger particle size of the F4 aerosol model compared with 
Table 2. Spectral SSA (upper) and asymmetry factor (lower) with respect to wavelength, Ångström exponent (AE), effective radius $\left(r_{\text {eff }}\right)$, and sphericity of the new aerosol models used for the test algorithm. H models $(0.85<\mathrm{SSA}<0.90)$ and M models $(0.90<\mathrm{SSA}<0.95)$ cover FMF ranging from 0.2 to 1.0 , while $\mathrm{N}$ models ( $\mathrm{SSA}>0.95$ ) cover from 0.3 to 1.0 . The minimum and maximum values are shown because of AOD dependence. The optical properties are interpolated to spectral response functions of MODIS bands in RTM calculations.

\begin{tabular}{|c|c|c|c|c|c|c|c|c|c|c|}
\hline $\begin{array}{l}\text { Model No. } \\
\text { (SSA, FMF) }\end{array}$ & $440 \mathrm{~nm}$ & $675 \mathrm{~nm}$ & $870 \mathrm{~nm}$ & $1020 \mathrm{~nm}$ & $1240 \mathrm{~nm}$ & $1640 \mathrm{~nm}$ & $2120 \mathrm{~nm}$ & $\mathrm{AE}$ & $r_{\text {eff }}(\mu \mathrm{m})$ & sphericity \\
\hline $\mathrm{H} 1$ & $0.875-0.879$ & $0.932-0.933$ & $0.940-0.946$ & $0.944-0.951$ & $0.990-0.991$ & $0.985-0.986$ & $0.994-0.995$ & $0.16-0.22$ & $0.76-1.08$ & $1-1 \%$ \\
\hline$(0.875,0.25)$ & $0.752-0.763$ & $0.723-0.733$ & $0.728-0.739$ & $0.732-0.742$ & $0.729-0.731$ & $0.733-0.734$ & $0.736-0.738$ & & & \\
\hline $\mathrm{H} 2$ & $0.877-0.877$ & $0.920-0.922$ & $0.929-0.932$ & $0.934-0.938$ & $0.989-0.989$ & $0.982-0.983$ & $0.993-0.993$ & $0.27-0.28$ & $0.61-0.63$ & $2-3 \%$ \\
\hline$(0.875,0.35)$ & $0.719-0.726$ & $0.696-0.698$ & $0.705-0.710$ & $0.716-0.720$ & $0.725-0.726$ & $0.731-0.732$ & $0.735-0.735$ & & & \\
\hline H3 & $0.874-0.884$ & $0.902-0.914$ & $0.916-0.925$ & $0.920-0.928$ & $0.988-0.988$ & $0.979-0.979$ & $0.992-0.992$ & $0.32-0.43$ & $0.53-0.54$ & $9-10 \%$ \\
\hline$(0.875,0.45)$ & $0.701-0.704$ & $0.674-0.679$ & $0.673-0.681$ & $0.690-0.699$ & $0.718-0.718$ & $0.727-0.728$ & $0.730-0.731$ & & & \\
\hline $\mathrm{H} 4$ & $0.877-0.880$ & $0.883-0.902$ & $0.898-0.913$ & $0.905-0.916$ & $0.986-0.986$ & $0.974-0.975$ & $0.991-0.991$ & $0.43-0.60$ & $0.47-0.50$ & $17-21 \%$ \\
\hline$(0.875,0.55)$ & $0.695-0.702$ & $0.664-0.667$ & $0.657-0.661$ & $0.674-0.675$ & $0.702-0.709$ & $0.715-0.720$ & $0.723-0.725$ & & & \\
\hline H5 & $0.873-0.873$ & $0.871-0.871$ & $0.881-0.881$ & $0.882-0.882$ & $0.984-0.984$ & $0.969-0.969$ & $0.989-0.989$ & $0.79-0.79$ & $0.45-0.45$ & $28-28 \%$ \\
\hline$(0.875,0.65)$ & $0.702-0.702$ & $0.659-0.659$ & $0.651-0.651$ & $0.654-0.654$ & $0.684-0.684$ & $0.704-0.704$ & $0.717-0.717$ & & & \\
\hline H6 & $0.875-0.882$ & $0.860-0.873$ & $0.855-0.865$ & $0.854-0.857$ & $0.981-0.982$ & $0.951-0.955$ & $0.982-0.984$ & $1.24-1.28$ & $0.34-0.36$ & $67-74 \%$ \\
\hline$(0.875,0.75)$ & $0.706-0.736$ & $0.643-0.659$ & $0.627-0.631$ & $0.627-0.634$ & $0.617-0.639$ & $0.642-0.665$ & $0.675-0.690$ & & & \\
\hline $\mathrm{H} 7$ & $0.874-0.880$ & $0.846-0.876$ & $0.827-0.868$ & $0.814-0.861$ & $0.975-0.979$ & $0.933-0.944$ & $0.974-0.978$ & $1.33-1.48$ & $0.28-0.32$ & $74-74 \%$ \\
\hline$(0.875,0.85)$ & $0.703-0.735$ & $0.618-0.663$ & $0.584-0.617$ & $0.580-0.614$ & $0.591-0.602$ & $0.622-0.623$ & $0.663-0.666$ & & & \\
\hline $\mathrm{H} 8$ & $0.877-0.881$ & $0.850-0.869$ & $0.814-0.858$ & $0.787-0.842$ & $0.966-0.969$ & $0.891-0.899$ & $0.947-0.949$ & $1.65-1.69$ & $0.21-0.23$ & $96-97 \%$ \\
\hline$(0.875,0.95)$ & $0.704-0.713$ & $0.601-0.630$ & $0.547-0.575$ & $0.523-0.546$ & $0.517-0.536$ & $0.526-0.530$ & $0.585-0.594$ & & & \\
\hline M1 & $0.909-0.912$ & $0.956-0.963$ & $0.962-0.971$ & $0.965-0.973$ & $0.991-0.991$ & $0.985-0.985$ & $0.994-0.994$ & $0.18-0.19$ & $0.70-0.78$ & $2-3 \%$ \\
\hline$(0.925,0.25)$ & $0.746-0.752$ & $0.723-0.730$ & $0.726-0.734$ & $0.732-0.741$ & $0.727-0.729$ & $0.732-0.733$ & $0.736-0.738$ & & & \\
\hline M2 & $0.912-0.914$ & $0.940-0.950$ & $0.950-0.959$ & $0.955-0.961$ & $0.989-0.990$ & $0.982-0.984$ & $0.993-0.994$ & $0.23-0.36$ & $0.62-0.76$ & $2-6 \%$ \\
\hline$(0.925,0.35)$ & $0.718-0.723$ & $0.690-0.703$ & $0.694-0.707$ & $0.706-0.715$ & $0.724-0.727$ & $0.731-0.734$ & $0.734-0.737$ & & & \\
\hline M3 & $0.916-0.916$ & $0.932-0.933$ & $0.941-0.942$ & $0.946-0.948$ & $0.987-0.988$ & $0.978-0.980$ & $0.992-0.992$ & $0.52-0.56$ & $0.52-0.60$ & $8-10 \%$ \\
\hline$(0.925,0.45)$ & $0.707-0.715$ & $0.681-0.687$ & $0.686-0.688$ & $0.698-0.700$ & $0.713-0.716$ & $0.725-0.727$ & $0.731-0.732$ & & & \\
\hline M4 & $0.922-0.923$ & $0.929-0.930$ & $0.935-0.936$ & $0.940-0.940$ & $0.985-0.985$ & $0.974-0.974$ & $0.990-0.990$ & $0.74-0.76$ & $0.45-0.47$ & $12-16 \%$ \\
\hline$(0.925,0.55)$ & $0.707-0.712$ & $0.670-0.673$ & $0.670-0.672$ & $0.683-0.685$ & $0.696-0.697$ & $0.714-0.715$ & $0.725-0.726$ & & & \\
\hline M5 & $0.922-0.922$ & $0.921-0.924$ & $0.925-0.927$ & $0.928-0.930$ & $0.983-0.983$ & $0.968-0.969$ & $0.988-0.988$ & $0.91-1.02$ & $0.38-0.43$ & $19-28 \%$ \\
\hline$(0.925,0.65)$ & $0.706-0.714$ & $0.656-0.660$ & $0.650-0.650$ & $0.659-0.661$ & $0.672-0.677$ & $0.696-0.701$ & $0.714-0.718$ & & & \\
\hline M6 & $0.923-0.924$ & $0.909-0.924$ & $0.905-0.924$ & $0.905-0.925$ & $0.980-0.980$ & $0.956-0.960$ & $0.984-0.985$ & $1.21-1.28$ & $0.34-0.35$ & $28-40 \%$ \\
\hline$(0.925,0.75)$ & $0.702-0.703$ & $0.639-0.641$ & $0.622-0.628$ & $0.629-0.633$ & $0.639-0.650$ & $0.671-0.678$ & $0.699-0.704$ & & & \\
\hline M7 & $0.929-0.929$ & $0.909-0.918$ & $0.896-0.909$ & $0.889-0.903$ & $0.974-0.977$ & $0.932-0.943$ & $0.973-0.977$ & $1.38-1.53$ & $0.28-0.31$ & $54-71 \%$ \\
\hline$(0.925,0.85)$ & $0.717-0.723$ & $0.637-0.652$ & $0.601-0.619$ & $0.595-0.611$ & $0.579-0.603$ & $0.611-0.631$ & $0.662-0.673$ & & & \\
\hline M8 & $0.929-0.934$ & $0.909-0.937$ & $0.888-0.934$ & $0.871-0.930$ & $0.968-0.970$ & $0.899-0.908$ & $0.950-0.951$ & $1.48-1.70$ & $0.23-0.26$ & $69-92 \%$ \\
\hline$(0.925,0.95)$ & $0.721-0.729$ & $0.639-0.660$ & $0.584-0.614$ & $0.557-0.589$ & $0.528-0.561$ & $0.526-0.540$ & $0.580-0.587$ & & & \\
\hline N1 & $0.949-0.959$ & $0.978-0.981$ & $0.980-0.983$ & $0.982-0.985$ & $0.991-0.992$ & $0.985-0.987$ & $0.994-0.994$ & $0.32-0.38$ & $0.62-0.71$ & $13-15 \%$ \\
\hline$(0.975,0.35)$ & $0.717-0.719$ & $0.698-0.698$ & $0.701-0.702$ & $0.709-0.709$ & $0.725-0.726$ & $0.730-0.731$ & $0.731-0.732$ & & & \\
\hline N2 & $0.948-0.959$ & $0.970-0.976$ & $0.976-0.981$ & $0.978-0.983$ & $0.990-0.990$ & $0.984-0.984$ & $0.993-0.993$ & $0.49-0.57$ & $0.58-0.62$ & $7-16 \%$ \\
\hline$(0.975,0.45)$ & $0.710-0.732$ & $0.686-0.698$ & $0.688-0.696$ & $0.697-0.705$ & $0.713-0.722$ & $0.722-0.730$ & $0.728-0.733$ & & & \\
\hline N3 & $0.953-0.961$ & $0.960-0.970$ & $0.964-0.972$ & $0.965-0.974$ & $0.988-0.988$ & $0.979-0.981$ & $0.990-0.991$ & $0.75-0.81$ & $0.42-0.45$ & $10-19 \%$ \\
\hline$(0.975,0.55)$ & $0.701-0.730$ & $0.664-0.684$ & $0.667-0.676$ & $0.680-0.685$ & $0.696-0.708$ & $0.708-0.720$ & $0.718-0.726$ & & & \\
\hline $\mathrm{N} 4$ & $0.959-0.963$ & $0.955-0.963$ & $0.952-0.965$ & $0.952-0.966$ & $0.986-0.987$ & $0.975-0.978$ & $0.988-0.989$ & $0.90-1.01$ & $0.36-0.41$ & $19-20 \%$ \\
\hline$(0.975,0.65)$ & $0.717-0.728$ & $0.660-0.674$ & $0.649-0.661$ & $0.658-0.666$ & $0.679-0.684$ & $0.699-0.702$ & $0.715-0.717$ & & & \\
\hline N5 & $0.961-0.963$ & $0.957-0.958$ & $0.953-0.955$ & $0.952-0.954$ & $0.983-0.984$ & $0.968-0.971$ & $0.985-0.985$ & $1.17-1.26$ & $0.32-0.35$ & $24-38 \%$ \\
\hline$(0.975,0.75)$ & $0.717-0.732$ & $0.649-0.665$ & $0.629-0.644$ & $0.634-0.646$ & $0.648-0.656$ & $0.674-0.680$ & $0.699-0.706$ & & & \\
\hline N6 & $0.964-0.968$ & $0.959-0.961$ & $0.954-0.956$ & $0.951-0.953$ & $0.981-0.982$ & $0.957-0.958$ & $0.978-0.979$ & $1.39-1.49$ & $0.28-0.31$ & $48-68 \%$ \\
\hline$(0.975,0.85)$ & $0.730-0.744$ & $0.652-0.671$ & $0.617-0.635$ & $0.610-0.624$ & $0.598-0.612$ & $0.625-0.630$ & $0.665-0.668$ & & & \\
\hline N7 & $0.969-0.970$ & $0.963-0.968$ & $0.956-0.963$ & $0.949-0.959$ & $0.978-0.980$ & $0.936-0.943$ & $0.961-0.963$ & $1.51-1.73$ & $0.24-0.28$ & $78-91 \%$ \\
\hline$(0.975,0.95)$ & $0.734-0.755$ & $0.653-0.699$ & $0.600-0.654$ & $0.573-0.626$ & $0.542-0.584$ & $0.536-0.546$ & $0.565-0.593$ & & & \\
\hline
\end{tabular}

the fine-mode of the new aerosol model counterparts for low AOD. As a result, general underestimation of AOD is expected from the C005 algorithm compared with the test algorithm, and this may have caused the underestimation of high AOD in the validation results represented in Remer et al. (2008).

A redundancy test is performed to ensure whether all the aerosol models result in distinct spectral reflectance feature to be selected by the retrieval procedure. The test is carried out by retrieving AOPs, using calculated TOA reflectances as a proxy of observation data for the whole LUT dimensions shown in Table 1 (total 283176 data points). Two different proxy data are created by adding maximum random error of $3 \%$ and $10 \%$. Figure 5 compares the exact solutions and the retrieved results. The data points with regard to various geometries and the other variables, except the target variable, are averaged at each nodal point and shown with one-standard deviation intervals. The comparison results show that each aerosol model (i.e. FMF and SSA) can be retrieved with small errors for the $3 \%$ error case, while 

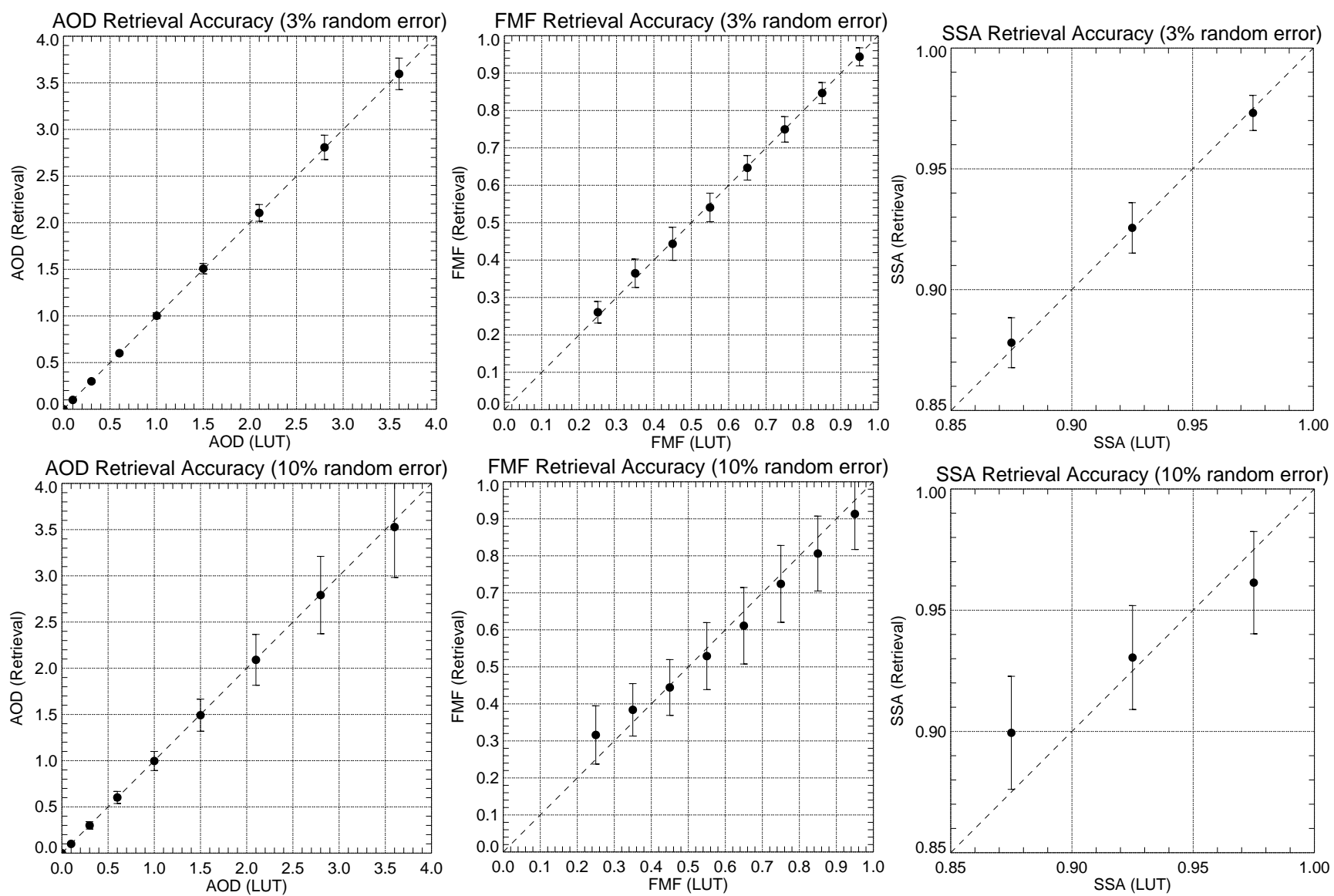

Fig. 5. Comparison between input variables (AOD, FMF, SSA) and retrieved variables from the present algorithm in LUT space. Tests are performed with synthesized data including maximum random error of $3 \%$ (upper) and $10 \%$ (lower). Mean and standard deviation values are shown for each calculation point for LUT.

significant misselection occurs for the $10 \%$ error case. The wrong retrieval is more prominent for SSA than FMF, showing lower accuracy in retrieving absorptivity than size information from MODIS. However, all the aerosol models are still required for the retrieval since highly-absorbing and non-absorbing aerosols are still discernable in some degree even for $10 \%$ error case.

\section{Results and evaluation}

The effects of the new aerosol models on AOD retrieval are evaluated by comparing the AODs from AERONET and MODIS data retrieved by the C005 and the test algorithm. Eight years of spectral reflectance data (2003-2010) observed from Aqua-MODIS are collected and processed to retrieve AOD using the new aerosol models. The AOD data from the $\mathrm{C} 005$ algorithm are also processed to compare with the AERONET observations, thereby allowing validation results from both algorithms to be compared. In this study, the "Effective_Optical_Depth_Average_Ocean" data in the MYD04 files are used for the C005 algorithm. Overall statistical scores and systematic errors are compared to characterize various error sources.

\subsection{Overall evaluation}

Figure 6 compares AODs between AERONET and MODIS over the global ocean from 2003 to 2010. Three different results retrieved from the $\mathrm{C} 005$ algorithm and the test algorithm using two different inversion procedures described in Sect. 2 are shown to investigate effects of new aerosol models and inversion methods on AOD retrieval accuracy. For this comparison, collocation was made within $\pm 30 \mathrm{~min}$ in time and $25 \mathrm{~km}$ in space similar to the method proposed by Ichoku et al. (2002). However, we sampled satellite pixels by calculating actual distances between each AERONET location and the MODIS pixels for both test and operational datasets, while Ichoku et al. (2002) selected $5 \times 5$ MODIS pixels with an AERONET station located in the middle of the grid regardless of viewing angle. A criterion is applied for the number of data points, which requires at least 5 and 2 data points for MODIS and AERONET, respectively. Because the test algorithm tended to retrieve more data than the 

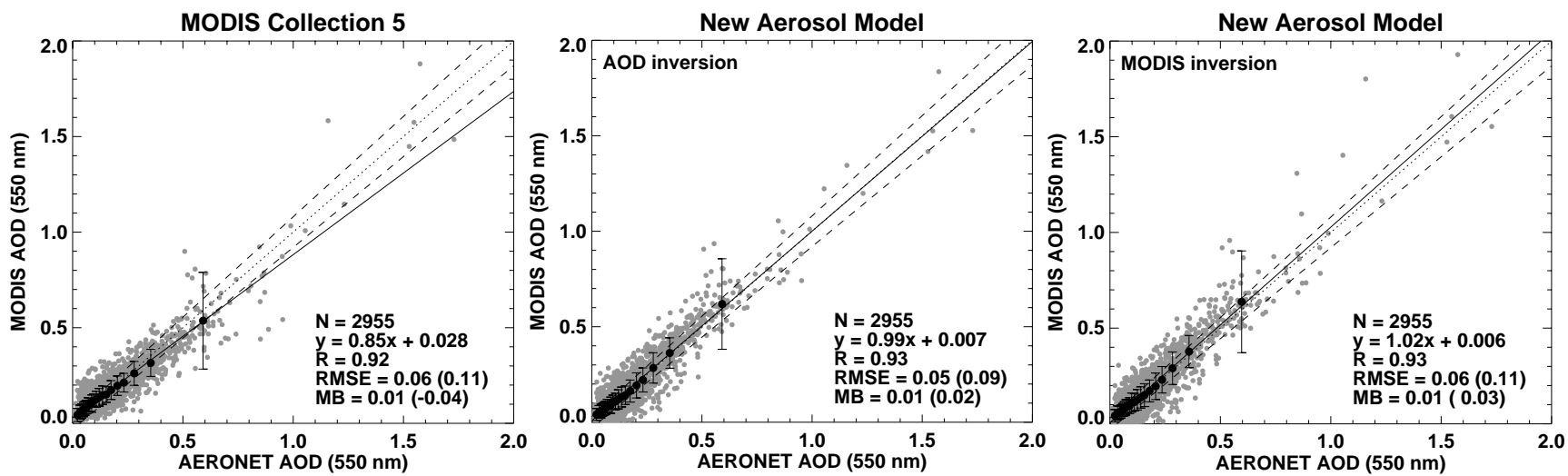

Fig. 6. Comparison of AOD between AERONET and MODIS over the global ocean for the period from 2003 to 2010. The MODIS AODs are from the C005 algorithm (left) and the test algorithm (middle and right) with new aerosol models. Two different inversion procedures using standard deviation of spectral AOD (middle) and MODIS operational inversion (right) are applied for the test algorithm. The collocation criteria of \pm 30 minutes in time and $25 \mathrm{~km}$ in space were used. The gray dots represent all data points, whereas black dots with onestandard deviation interval represent mean AODs in 20 equal-number-of-data bins with respect to the AERONET data. The solid line is from the regression equation, while the dotted and dashed lines are the one-to-one line and the MODIS expected error (EE) line showing $\pm(0.03+0.05 \times$ AOD $)$, respectively. Only data points overlapping between the two algorithms are compared. Originally, the number of data points was 3106 for the C005 algorithm and 3578 for the test algorithm. The statistics shown are the Pearson coefficient $(R)$, root mean squared error (RMSE), mean bias (MB), and the number of data points $(N)$.

Table 3. Statistics for a comparison of AOD retrieved from the MODIS C005 algorithm and AERONET observations from 2003 to 2010 over the global ocean. The numbers in the parentheses are for AOD (AERONET) $>0.3$.

\begin{tabular}{llllllllll}
\hline $\begin{array}{l}\text { MODIS } \\
\text { OP }\end{array}$ & 2003 & 2004 & 2005 & 2006 & 2007 & 2008 & 2009 & 2010 & Overall \\
\hline$R$ & 0.91 & 0.93 & 0.92 & 0.87 & 0.94 & 0.92 & 0.92 & 0.94 & 0.92 \\
Slope & 0.78 & 0.87 & 0.82 & 0.77 & 0.9 & 0.9 & 0.88 & 0.87 & 0.85 \\
y-intercept & 0.04 & 0.02 & 0.03 & 0.04 & 0.02 & 0.03 & 0.03 & 0.03 & 0.03 \\
Percentage & $66 \%$ & $62 \%$ & $62 \%$ & $62 \%$ & $58 \%$ & $62 \%$ & $64 \%$ & $65 \%$ & $62 \%$ \\
within EE & $(38 \%)$ & $(37 \%)$ & $(40 \%)$ & $(40 \%)$ & $(28 \%)$ & $(43 \%)$ & $(44 \%)$ & $(54 \%)$ & $(39 \%)$ \\
RMSE & 0.06 & 0.07 & 0.05 & 0.05 & 0.06 & 0.06 & 0.05 & 0.05 & 0.06 \\
& $(0.11)$ & $(0.13)$ & $(0.09)$ & $(0.10)$ & $(0.11)$ & $(0.10)$ & $(0.07)$ & $(0.07)$ & $(0.11)$ \\
MB & 0.00 & 0.00 & 0.00 & 0.00 & 0.01 & 0.01 & 0.02 & 0.01 & 0.01 \\
& $(-0.06)$ & $(-0.05)$ & $(-0.06)$ & $(-0.06)$ & $(-0.02)$ & $(-0.01)$ & $(-0.02)$ & $(-0.04)$ & $(-0.04)$ \\
$N$ & 393 & 451 & 441 & 346 & 377 & 336 & 347 & 264 & 2955 \\
& $(50)$ & $(77)$ & $(47)$ & $(30)$ & $(38)$ & $(30)$ & $(29)$ & $(24)$ & $(325)$ \\
\hline
\end{tabular}

C005 algorithm due to the absence of a quality-control procedure used in C005 algorithm, only overlapping data retrieved by both algorithms were used for quantitative comparisons.

The validation results show that the AOD data from the C005 algorithm are highly correlated with the observations, but, on average, tend to be underestimated, with a Pearson coefficient of 0.92 and a regression slope of 0.85 . The negative bias of the slope is caused by overestimation in the low AOD regime $(\mathrm{AOD}<0.2)$ and underestimation in the high AOD regime (AOD > 0.3). Meanwhile, the new aerosol models improve the slope significantly $(0.99-1.02)$ with a comparable correlation coefficient (0.93) regardless of the inversion methods. Only small differences are observed between the two results, showing a slight increase in statis- tics for the new inversion compared with the C005 inversion. However, the new inversion may not guarantee improved results for the $\mathrm{C} 005$ algorithm because of differences in the LUT. Since the difference is negligible between the two methods, only results from the new inversion will be shown for further analyses. From the statistics summarized in Tables 3 and 4, the aerosol models clearly improve almost all the statistics analysed in this study. The slope and the percentage of data within an expected error improved from $62 \%$ to $64 \%$ overall and from $39 \%$ to $51 \%$ for AOD $>0.3$. These improvements are particularly noticeable for the high AOD regime at which the aerosol signal dominates the other contributions, such as Rayleigh scattering and surface reflectance. The major reason for the improvement in AOD 
Table 4. Same as in Table 3 except for the test algorithm.

\begin{tabular}{llllllllll}
\hline This study & 2003 & 2004 & 2005 & 2006 & 2007 & 2008 & 2009 & 2010 & Overall \\
\hline$R$ & 0.94 & 0.96 & 0.93 & 0.88 & 0.94 & 0.92 & 0.93 & 0.94 & 0.93 \\
Slope & 1.01 & 1.00 & 0.97 & 0.91 & 1.01 & 1.00 & 1.01 & 1.00 & 0.99 \\
y-intercept & 0.01 & 0.01 & 0.01 & 0.02 & 0.01 & 0.01 & 0.01 & 0.00 & 0.01 \\
Percentage & $64 \%$ & $65 \%$ & $65 \%$ & $62 \%$ & $59 \%$ & $61 \%$ & $66 \%$ & $67 \%$ & $64 \%$ \\
within EE & $(50 \%)$ & $(55 \%)$ & $(48 \%)$ & $(43 \%)$ & $(36 \%)$ & $(60 \%)$ & $(51 \%)$ & $(70 \%)$ & $(51 \%)$ \\
RMSE & 0.05 & 0.05 & 0.05 & 0.06 & 0.06 & 0.06 & 0.05 & 0.05 & 0.05 \\
& $(0.08)$ & $(0.08)$ & $(0.08)$ & $(0.10)$ & $(0.12)$ & $(0.10)$ & $(0.09)$ & $(0.07)$ & $(0.09)$ \\
MB & 0.01 & 0.01 & 0.00 & 0.00 & 0.01 & 0.01 & 0.01 & 0.00 & 0.01 \\
& $(0.02)$ & $(0.01)$ & $(0.00)$ & $(-0.01)$ & $(0.05)$ & $(0.04)$ & $(0.02)$ & $(0.01)$ & $(0.02)$ \\
$N$ & 393 & 451 & 441 & 346 & 377 & 336 & 347 & 264 & 2955 \\
& $(50)$ & $(77)$ & $(47)$ & $(30)$ & $(38)$ & $(30)$ & $(29)$ & $(24)$ & $(325)$ \\
\hline
\end{tabular}
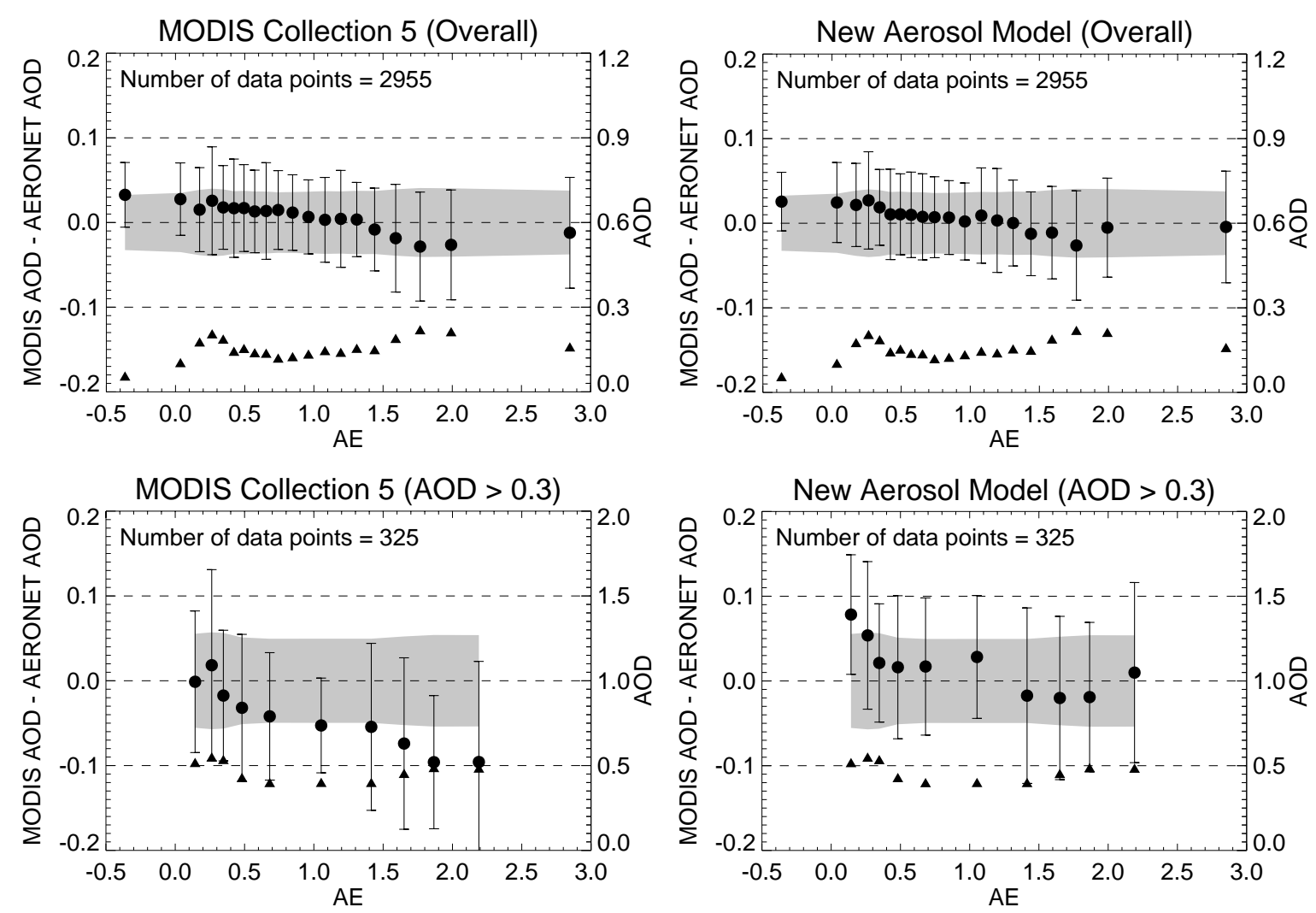

Fig. 7. AE dependence of retrieval errors for the C005 algorithm (left) and the test algorithm (right) for overall data (upper) and data for AOD $>0.3$ (lower). The data are sorted in 20 and 10 equal-number-of-data bins for the overall case and high AOD case, respectively. The dots and bars represent mean and one-standard deviation intervals of the retrieval errors, respectively, while the triangles represent the mean AOD from AERONET in each bin.

retrieval is the consideration of absorbing fine-mode aerosols and changing the size distribution as a function of AOD. Both factors are expected to increase AOD for a given TOA reflectance as shown in Fig. 4 and other previous studies (Levy et al., 2007b; Wang and Martin, 2007; Jethva et al., 2010). Note that the current MODIS algorithm adopts four different water-soluble aerosol models with fixed radii insensitive to AOD for the fine-mode cluster.

\subsection{Error characteristics}

Errors in AOD can arise from various sources including incorrect assumptions about surface reflectance and aerosol type, status of sensor calibration, observation geometry, etc. In addition, specific observation environments can bias results. Levy et al. (2010) evaluated the C005 over-land AOD data with regard to AE, cloud fraction, surface type 

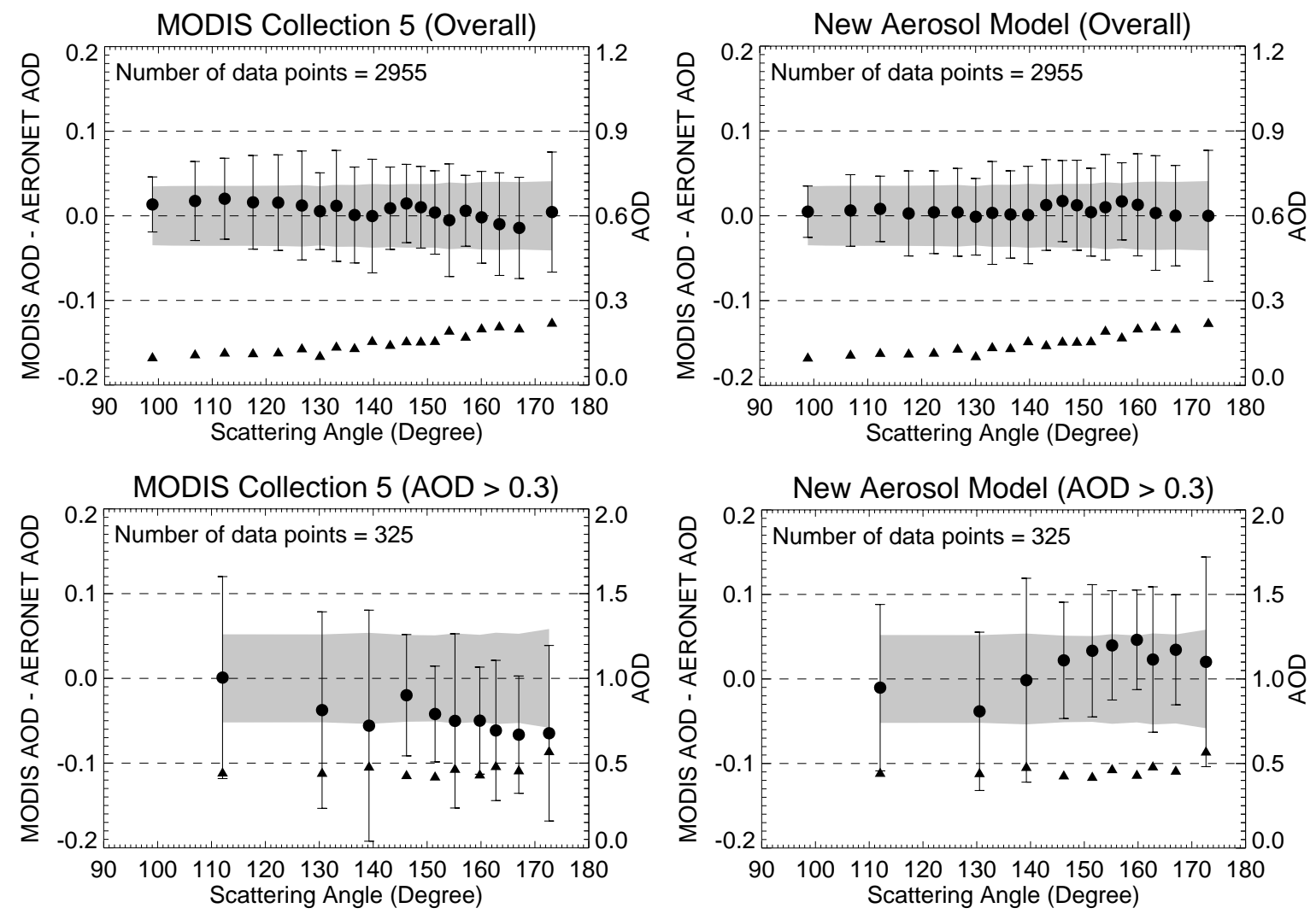

Fig. 8. Scattering angle dependence of retrieval errors for the C005 algorithm (left) and the test algorithm (right) for overall data (upper) and data for $\mathrm{AOD}>0.3$ (lower).

characteristics, and observation geometry to characterize systematic error sources. Thus, the analyses to be presented here together with the work of Levy et al. (2010) represent a complete evaluation of the MODIS data retrieved over land and ocean.

Figure 7 shows the AE dependence of the retrieval errors for the $\mathrm{C} 005$ and the test algorithms. The data were sorted into 20 and 10 equal-number-of-data bins for the overall data and AOD $>0.3$, respectively. As shown in the result, the $\mathrm{C} 005$ algorithm tends to overestimate coarse-dominated AOD $(\mathrm{AE}<0.8)$ and underestimate fine-dominated AOD $(\mathrm{AE}>1.6)$. The underestimation of fine-dominated AOD worsens for high AOD cases, suggesting that the underestimation of high AOD from the C005 algorithm shown in Fig. 6 is mainly caused by fine-dominated cases, while reliable retrievals are performed for dust aerosols. The retrieved AODs are less stable (stability inferred by the magnitude of one standard deviation interval) for fine-dominated AOD than coarse-dominated AOD, while stable retrieval is observed for $0.75<\mathrm{AE}<1.4$ partially due to the relatively low AOD. In the case of AOD $>0.3$, although there are systematic underestimations, the algorithm shows small mean biases $(\mathrm{MBs})$ for strong dust events $(\mathrm{AE}<0.4)$ with a higher stability than the fine-dominated case $(\mathrm{AE}>1.4)$.
The AE dependence of MB for the test algorithm is reduced overall compared with the C005 algorithm, but the test algorithm still has a tendency to overestimate coarsedominated AOD and to underestimate fine-dominated AOD. The $\mathrm{AE}$ dependence is reduced further for $\mathrm{AOD}>0.3$, but the AODs are distinctly overestimated for a coarsedominated case $(\mathrm{AE}<0.3)$. The improvement in the finedominated AOD for a high AOD case can be explained by the inclusion of the absorbing aerosol models and size distribution shift. As shown in Fig. 4, both effects can result in overestimation of AOD. In this case, the overestimation resulted in an improvement in underestimated AOD from the C005 algorithm. However, the standard deviation of the retrieval errors is slightly lower than that of the C005 algorithm for the coarse-dominated regime, while the standard deviation is similar between the two algorithms for the finedominated regime $(\mathrm{AE}>1.3)$. As a result, the new aerosol models can be inferred to mitigate systematic errors (i.e., $\mathrm{MB})$ compared with the $\mathrm{C} 005$ algorithm except for severe dust events (AOD $>0.3, \mathrm{AE}<0.3$ ).

Figure 8 shows the scattering angle dependence of the retrieval errors. For the overall case of the C005 algorithm, the MB decreases gradually with increasing scattering angle and mean AOD. The decrease is a result of 

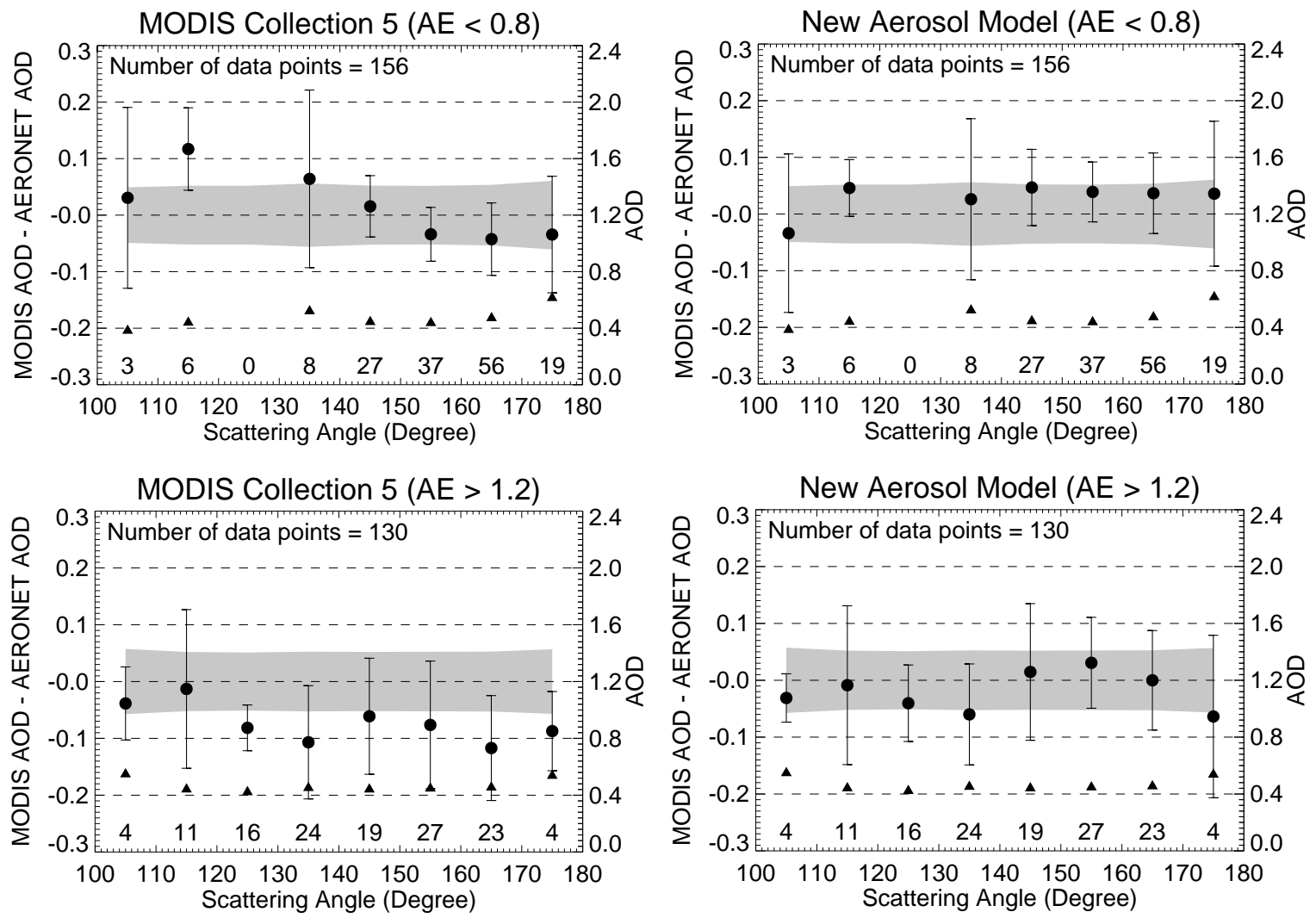

Fig. 9. Scattering angle dependence of the retrieval error for C005 algorithm (left) and test algorithm (right) for AE $<0.8$ (upper) and $\mathrm{AE}>1.2$ (lower). Only data with $\mathrm{AOD}>0.3$ were used in this comparison. The symbols and lines are the same as those described in the legend to Fig. 7. Note that the data were sorted in each $10^{\circ}$ interval of the scattering angle to highlight differences in the side-scattering-angle range $\left(100-130^{\circ}\right)$ where the number of data points is low. The numbers on the $\mathrm{x}$-axis represent the number of data points in each bin.

combined effects of the systematic overestimation of low AOD cases $(\mathrm{AOD}<0.2)$ and the underestimation of finedominated AOD with increasing AOD. In contrast, the scattering angle dependence of the $\mathrm{MB}$ is much lower in the test algorithm, indicating improved retrieval accuracy. Only two distinct positive peaks are present for $140^{\circ}<\Theta<165^{\circ}$. For AOD $>0.3$, the C005 algorithm shows systematic underestimation, while the test algorithm shows positive $\mathrm{MB}$ for $\Theta>140^{\circ}$ and negative MB for $\Theta<140^{\circ}$. The underestimation in the $\mathrm{C} 005$ algorithm tends to worsen with increasing scattering angle, partially due to increasing AOD, while high AOD seems to correspond to low MB in the test algorithm.

For a more detailed explanation on the scattering angle dependence of the retrieval errors, additional comparisons for aerosol type information are shown in Fig. 9. Note that neglecting the nonsphericity of dust particles results in underestimation of AOD in the back-scattering direction, and overestimation in the side-scattering direction due to the difference in scattering phase function between spherical and nonspherical particles. For a dust-dominated case $(\mathrm{AE}<0.8)$, the data provided by the $\mathrm{C} 005$ algorithm shows an imprint of the difference in phase functions between spherical and nonspherical particles, while the new aerosol models significantly re- duce the scattering angle dependence. The new aerosol models, however, systematically overestimate the AOD regardless of the scattering angle. Consequently, the small MB of the C005 algorithm for coarse-dominated AOD, represented in Fig. 7, can be explained by cancellation of the positive and negative errors, while the test algorithm systematically overestimates AOD. For anthropogenic aerosols (AE > 1.2), neither algorithm shows distinct features related to differences in the phase function, while the systematic underestimation of the $\mathrm{C} 005$ algorithm in the back-scattering direction is significantly reduced by the test algorithm.

The retrieval results are further categorized with respect to the SSA in order to understand the impact of aerosol absorption on retrieval accuracy. Figure 10 shows the MB of the retrieved AODs for SSA. The AE constraint is also applied to separate fine-dominated and coarse-dominated cases. The daily mean SSA values from AERONET are used in this investigation since insufficient data points are gathered if a time constraint is applied. Note that AERONET Level 2 SSA values are retrieved for AOD $(440 \mathrm{~nm})>0.4$. Thus, fine-dominated $(\mathrm{AE}>1.2)$ and coarse-dominated cases $(\mathrm{AE}<0.8)$ represent anthropogenic and dust events, respectively. For coarse-dominated case, no 

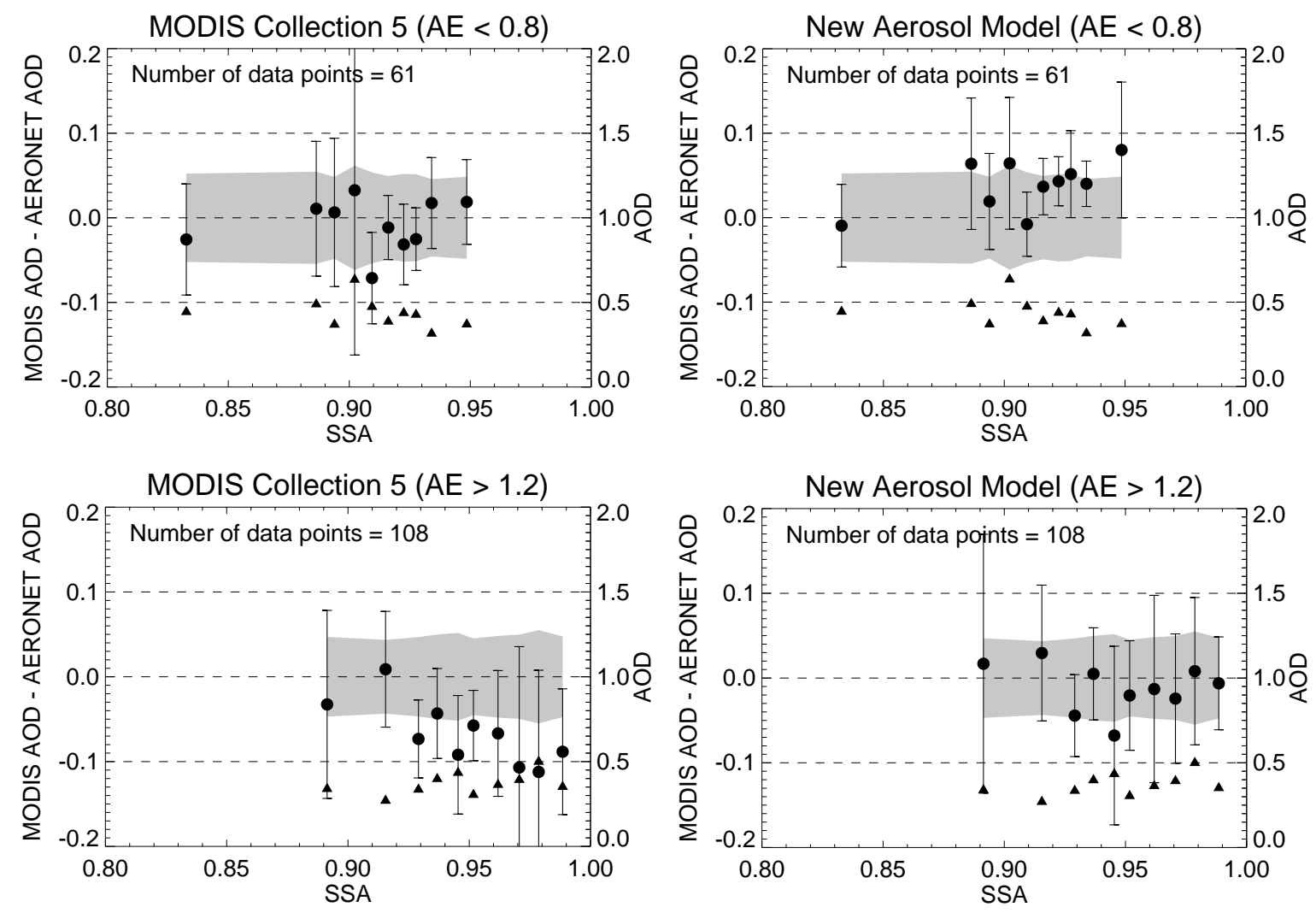

Fig. 10. SSA dependence of retrieval errors for the C005 algorithm (left) and the test algorithm (right). AERONET Level 2 SSA values are retrieved for AOD $(440 \mathrm{~nm})>0.4$.

distinct dependence on SSA is observed for either dataset, but systematic overestimation of dust AOD from the test algorithm is highlighted. However, smaller standard deviations from the test algorithm indicate systematic error, while C005 algorithm shows somewhat larger dispersions. On the other hand, relatively strong absorptivity dependence is observed in the $\mathrm{C} 005$ algorithm for fine-dominated case, showing increasing underestimation tendency with SSA. In fact, the result is confusing because no highly absorbing aerosol model is included in the $\mathrm{C} 005$ algorithm and underestimation of absorptivity normally results in underestimation of AOD. However, the complexity of error sources can produce the anomaly. As found in this study, both absorptivity and particle size assumed in the retrieval algorithm can cause errors in the retrieved AOD. In addition, errors in the retrieved FMF can result in additional error in the AOD. The results from the test algorithm show relatively accurate AOD retrieval with mitigated SSA dependence.

The sensitivity of TOA reflectance to AOD increases with air mass because of the increasing optical path. Thus, the air mass factor (AMF), defined by $m_{\text {Sun }} \times m_{\text {satellite }}$ where $m=\sec (\theta)$, can affect retrieval accuracy. Figure 11 shows the retrieval error dependence on the AMF. We expected the retrieval errors to decrease with the AMF because of increased sensitivity; however, the pattern is more complicated because the retrieval errors are functions of AOD, $\Theta$, and aerosol type. For both algorithms, retrieval stability increases (decreasing standard deviation) with the AMF partially because of increasing sensitivity. However, the MB shows different behavior; it decreases in the negative regime and then increases in the positive regime with increasing AMF for $\mathrm{AMF}<1.6$, and then gradually decreases with increasing AMF. For the high AOD case, however, a high AMF does not guarantee retrieval stability; the standard deviation is uncorrelated with the AMF. For the test algorithm, the MB tends to decrease with increasing AMF except for the bifurcation observed for $\mathrm{AMF}<1.5$, while no dependency is observed for the $\mathrm{C} 005$ algorithm.

\section{Conclusions}

We quantitatively assessed the impact of the use of new aerosol models on AOD retrieval from spectral reflectance observed by Aqua-MODIS over the global ocean for the period from 2003 to 2010. AERONET inversion data and the optical property data of tri-axial ellipsoidal dust particles from an existing database were used to compile AOPs in order to calculate LUTs, which include various aerosol types from absorbing to non-absorbing $(0.85<\mathrm{SSA}<1.00)$ 

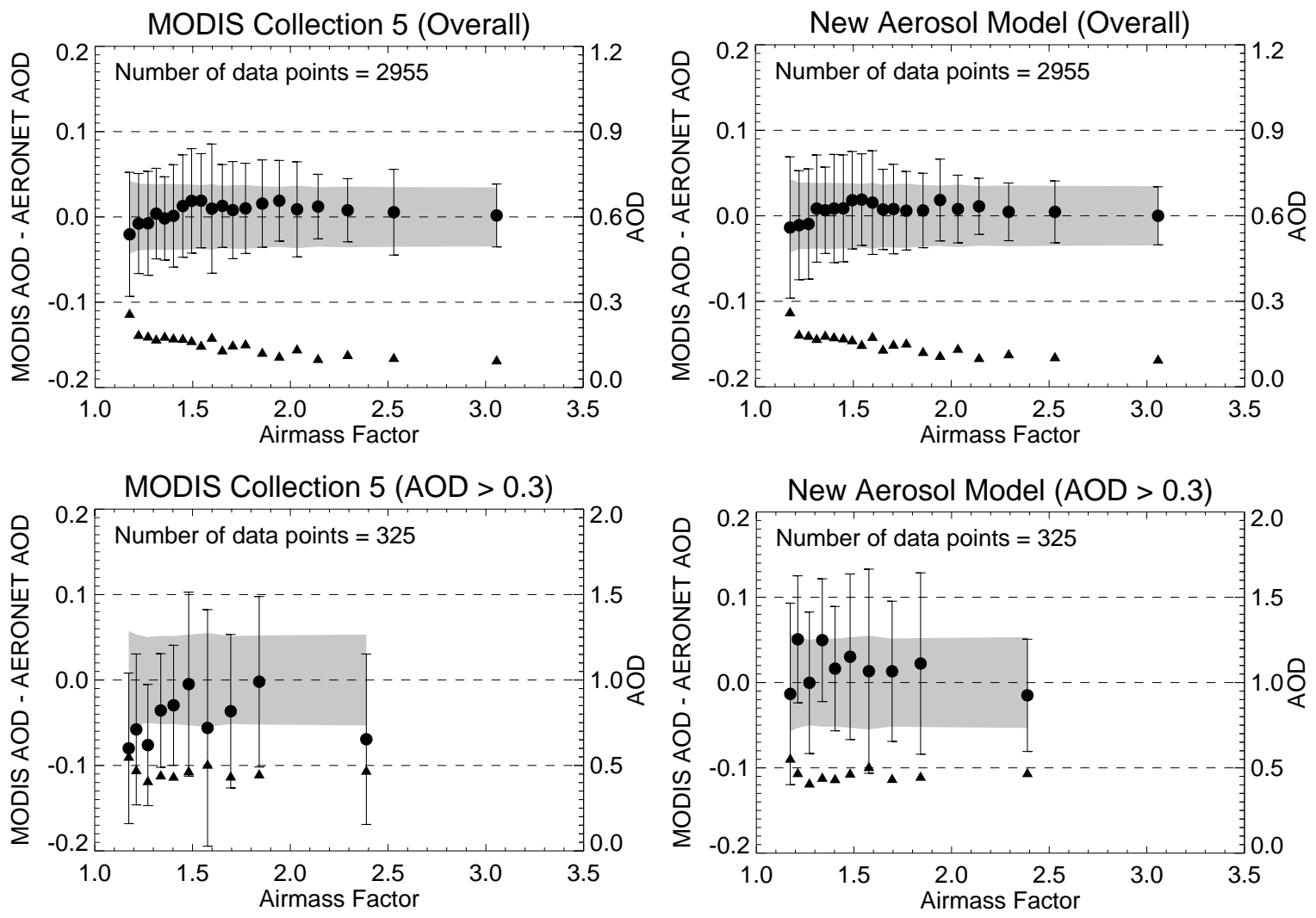

Fig. 11. Air-mass factor $\left(m_{\text {Sun }} \times m_{\text {satellite, }}\right.$ where $\left.m=\sec [\theta]\right)$ dependence of retrieval errors for the C005 algorithm (left) and the test algorithm (right) for overall data (upper) and data for AOD $>0.3$ (lower).

and from fine- to coarse-dominated $(0.2$ or $0.3<\mathrm{FMF}<1.0)$. Because the MODIS C005 algorithm considers only watersoluble aerosols with/without humidity for fine-mode and sea salt/dust for coarse-mode, a noticeable difference was observed in AOD retrieval using the new algorithm with the consideration of various absorptivities and the size distribution change as a function of AOD.

Validation of the algorithms by using eight years of data revealed the new aerosol models to improve the AOD, with a regression equation of $y=0.99 x+0.007$ and a Pearson coefficient of 0.93 compared to $y=0.85 x+0.028$ and 0.92 for the $\mathrm{C} 005$ algorithm. The percentage of AOD data falling within the expected error was $64 \%$ for the test algorithm and $62 \%$ for the current operational algorithm. In particular, improvements were noted in the high AOD regime (AOD > 0.3) where the aerosol signal dominates the surface signal with a $12 \%$ increase in the number of reliable data points within the expected error. The root mean squared error (RMSE) and MB were also improved by the use of the new aerosol models.

To further characterize the retrieval errors, the data were validated with respect to $\mathrm{AE}$, scattering angle, SSA, and AMF. The new aerosol models mitigated the dependence of $\mathrm{MB}$ (systematic error) on the aforementioned parameters. However, the coarse particle-dominated AOD was still overestimated and the fine particle-dominated AOD was under- estimated. While the systematic overestimation of the coarse particle-dominated AOD increased for the high AOD case, the results for the fine particle-dominated AOD cases were similar compared to the overall case. Retrieval stability, however, was higher for the coarse particle-dominated case than the fine particle-dominated case, partially due to the wider variability in the optical properties of the fine-mode aerosols. In addition, the constrained analyses revealed the test algorithm to significantly reduce the scattering angle dependence of the retrieval error for dust-dominated cases $(\mathrm{AE}<0.8$, AOD > 0.3), partially due to improved treatment of the nonsphericity of dust particles and mitigated SSA dependence for fine-dominated cases. The standard deviation of the retrieval errors for the overall case tended to decrease with AMF as expected, but no distinct tendency was observed for AOD $>0.3$. Our validation results indicate that the aerosol models adopted in the current MODIS operational algorithm need to be updated to achieve better accuracy. Further analyses on FMF and SSA retrievals are required to obtain a better understanding of the various error sources contributing to AOD retrieval and corresponding improvements in the aerosol retrieval algorithms. 
Acknowledgements. This research was supported by the Eco Innovation Program of KEITI(ARQ201204015), Korea. We thank the principal investigators and their staff for establishing and maintaining the MODIS and AERONET sites used in this investigation. Jhoon Kim and Jaehwa Lee received partial support from the Brain Korea 21 (BK21) program. Ping Yang acknowledges support from the National Science Foundation (ATM-0803779) of the United States.

Edited by: C. H. Song

\section{References}

Bi, L., Yang, P., Kattawar, G. W., and Kahn, R.: Single-scattering properties of triaxial ellipsoidal particles for a size parameter range from the Rayleigh to geometric-optics regimes, Appl. Opt., 48, 114-126, 2009.

Bohren, C. F. and Huffman, D. R.: Absorption and scattering of light by small particles, New York, Wiley-Interscience, 1983.

Chu, D. A., Kaufman, Y. J., Ichoku, C., Remer, L. A., Tanré, D., and Holben, B. N.: Validation of MODIS aerosol optical depth retrieval over land, Geophys. Res. Lett., 29, 8007, doi:10.1029/2001GL013205, 2002.

Dubovik, O. and King, M. D.: A flexible inversion algorithm for retrieval of aerosol optical properties from sun and sky radiance measurements, J. Geophys. Res., 105, 20673-20696, 2000.

Dubovik, O., Holben, B. N., Eck, T. F., Smirnov, A., Kaufman, Y. J., King, M. D., Tanré, D., and Slutsker, I.: Variability of absorption and optical properties of key aerosol types observed in worldwide locations, J. Atmos. Sci., 59, 590-608, 2002.

Dubovik, O., Sinyuk, A., Lapyonok, T., Holben, B. N., Mishchenko, M., Yang, P., Eck, T. F., Volten, H., Muñoz, O., Veihelmann, B., van der Zande, W. J., Leon, J.-F., Sorokin, M., and Slutsker, I.: Application of spheroid models to account for aerosol particle nonsphericity in remote sensing of desert dust, J. Geophys. Res., 111, D11208, doi:10.1029/2005JD006619, 2006.

Hess, M., Koepke, P., and Schult, I.: Optical properties of aerosols and clouds: The software package OPAC, B. Am. Meteorol. Soc., 79, 831-844, 1998.

Higurashi, A. and Nakajima, T.: Development of a two-channel aerosol retrieval algorithm on a global scale using NOAA AVHRR, J. Atmos. Sci., 56, 924-941, 1999.

Higurashi, A. and Nakajima, T.: Detection of aerosol types over the East China Sea near Japan from four-channel satellite data, Geophys. Res. Lett., 29, 1836, doi:10.1029/2002GL015357, 2002.

Holben, B. N., Eck, T. F., Slutsker, I., Tanré, D., Buis, J. P., Setzer, A., Vermote, E., Reagan, J. A., Kaufman, Y. J., Nakajima, T., Lavenu, F., Jankowiak, I., and Smirnov, A.: AERONET - A federated instrument network and data archive for aerosol characterization, Remote Sens. Environ., 66, 1-16, 1998.

Hsu, N. C., Tsay, S. C., King, M. D., and Herman, J. R.: Aerosol retrievals over bright-reflecting source regions, IEEE T. Geosci. Remote Sens., 42, 557-569, 2004.

Hsu, N. C., Tsay, S. C., King, M. D., and Herman, J. R.: Deep blue retrievals of Asian aerosol properties during ACE-Asia, IEEE T. Geosci. Remote Sens., 44, 3180-3195, 2006.

Ichoku, C., Chu, D. A., Mattoo, S., Kaufman, Y. J., Remer, L. A., Tanré, D., Slutsker, I., and Holben, B. N.: A spatio-temporal approach for global validation and analysis of MODIS aerosol products, Geophys. Res. Lett., 29, 8006, doi:10.1029/2001GL013206, 2002.

IPCC, Climate Change 2007: The Physical Science Basis, Contribution of Working Group I to the Fourth Assessment Report of the Intergovernmental Panel on Climate Change, edited by: Solomon, S., Qin, D., Manning, M., Chen, Z., Marquis, M., Averyt, K. B., Tignor, M., and Miller, H. L., Cambridge University Press, Cambridge, United Kingdom and New York, NY, USA, 2007.

Jethva, H., Satheesh, S. K., Srinivasan, J., and Levy, R. C.: Improved retrieval of aerosol size-resolved properties from moderate resolution imaging spectroradiometer over India: Role of aerosol model and surface reflectance, J. Geophys. Res., 115, D18213, doi:10.1029/2009JD013218, 2010.

Kaufman, Y. J., Tanré, D., Remer, L. A., Vermote, E. F., Chu, A., and Holben, B. N.: Operational remote sensing of tropospheric aerosol over land from EOS moderate resolution imaging spectroradiometer, J. Geophys. Res., 102, 17051-17067, 1997.

Kim, J., Lee, J., Lee, H. C., Higurashi, A., Takemura, T., and Song, C. H.: Consistency of the aerosol type classification from satellite remote sensing during the Atmospheric Brown Cloud - East Asia Regional Experiment campaign, J. Geophys. Res., 112, D22S33, doi:10.1029/2006JD008201, 2007.

Kim, J., Yoon, J.-M., Ahn, M. H., Sohn, B. J., and Lim, H. S.: Retrieving aerosol optical depth using visible and mid-IR channels from geostationary satellite MTSAT-1R, Int. J. Remote Sens., 29, 6181-6192, 2008.

Knapp, K. R., Vonder Haar, T. H., and Kaufman, Y. J.: Aerosol optical depth retrieval from GOES-8: Uncertainty study and retrieval validation over South America, J. Geophys. Res., 107, D74055, doi:10.1029/2001JD000505, 2002.

Lee, J., Kim, J., Song, C. H., Kim, S. B., Chun, Y., Sohn, B. J., and Holben, B. N.: Characteristics of aerosol types from AERONET sunphotometer measurements, Atmos. Environ., 44, 3110-3117, doi:10.1016/j.atmosenv.2010.05.035, 2010a.

Lee, J., Kim, J., Song, C. H., Ryu, J.-H., Ahn, Y.-H., and Song, C. K.: Algorithm for retrieval of aerosol optical properties over the ocean from the geostationary ocean color imager, Remote Sens. Environ., 114, 1077-1088, doi:10.1016/j.rse.2009.12.021, $2010 b$.

Levy, R. C., Remer, L. A., and Dubovik, O.: Global aerosol optical properties and application to Moderate Resolution Imaging Spectroradiometer aerosol retrieval over land, J. Geophys. Res., 112, D13210, doi:10.1029/2006JD007815, 2007a.

Levy, R. C., Remer, L. A., Mattoo, S., Vermote, E. F., and Kaufman, Y. J.: Second-generation operational algorithm: Retrieval of aerosol properties over land from inversion of Moderate Resolution Imaging Spectroradiometer spectral reflectance, J. Geophys. Res., 112, D13211, doi:10.1029/2006JD007811, 2007b.

Levy, R. C., Remer, L. A., Kleidman, R. G., Mattoo, S., Ichoku, C., Kahn, R., and Eck, T. F.: Global evaluation of the Collection 5 MODIS dark-target aerosol products over land, Atmos. Chem. Phys., 10, 10399-10420, doi:10.5194/acp-10-10399-2010, 2010.

Mayer, B. and Kylling, A.: Technical note: The libRadtran software package for radiative transfer calculations - description and examples of use, Atmos. Chem. Phys., 5, 1855-1877, doi:10.5194/acp-5-1855-2005, 2005.

Meng, Z., Yang, P., Kattawar, G. W., Bi, L., Liou, K. N., and Laszlo, I.: Single-scattering properties of tri-axial ellipsoidal 
mineral dust aerosols: A database for application to radiative transfer calculations, J. Aerosol Sci., 41, 501-512, doi:10.1016/j.jaerosci.2010.02.008, 2010.

Mielonen, T., Arola, A., Komppula, M., Kukkonen, J., Koskinen, J., de Leeuw, G., and Lehtinen, K. E. J.: Comparison of CALIOP level 2 aerosol subtypes to aerosol types derived from AERONET inversion data, Geophys. Res. Lett., 36, L18804, doi:10.1029/2009GL039609, 2009.

Mishchenko, M. I. and Travis, L. D.: Capabilities and limitations of a current FORTRAN implementation of the T-matrix method for randomly oriented rotationally symmetric scatterers, J. Quant. Spectrosc. Ra., 60, 309-324, 1998.

Mishchenko, M. I., Geogdzhayev, I. V., Cairns, B., Rossow, W. B., and Lacis, A. A.: Aerosol retrievals over the ocean by use of channels 1 and 2 AVHRR data: Sensitivity analysis and preliminary results, Appl. Opt., 38, 7325-7341, 1999.

Pope, C. A. and Dockery, D. W.: Health effects of fine particulate air pollution: Lines that connect, J. Air Waste Manage., 56, 709742, 2006.

Remer, L. A., Tanré, D., Kaufman, Y. J., Ichoku, C., Mattoo, S., Levy, R., Chu, D. A., Holben, B., Dubovik, O., Smirnov, A., Martins, J. V., Li, R.-R., and Ahmad, Z.: Validation of MODIS aerosol retrieval over ocean, Geophys. Res. Lett., 29, 8008, doi:10.1029/2001GL013204, 2002.

Remer, L. A., Kaufman, Y. J., Tanré, D., Mattoo, S., Chu, D. A., Martins, J. V., Li, R.-R., Ichoku, C., Levy, R. C., Kleidman, R. G., Eck, T. F., Vermote, E., and Holben, B. N.: The MODIS aerosol algorithm, products and validation, J. Atmos. Sci., 62, 947-973, 2005.

Remer, L. A., Tanré, D., and Kaufman, Y. J.: Algorithm for remote sensing of tropospheric aerosol from MODIS: Collection 5, MODIS Algorithm Theoretical Basis Document, http: //modis-atmos.gsfc.nasa.gov/MOD04_L2/atbd.html, 2006.
Remer, L. A., Kleidman, R. G., Levy, R. C., Kaufman, Y. J., Tanré, D., Mattoo, S., Martins, J. V., Ichoku, C., Koren, I., Yu, H., and Holben, B. N.: Global aerosol climatology from the MODIS satellite sensors, J. Geophys. Res., 113, D14S07, doi:10.1029/2007JD009661, 2008.

Tanré, D., Kaufman, Y. J., Herman, M., and Mattoo, S.: Remote sensing of aerosol properties over oceans using the MODIS/EOS spectral radiances, J. Geophys. Res., 102, 16971-16988, 1997.

Wang, J., Christopher, S. A., Brechtel, F., Kim, J., Schmid, B., Redemann, J., Russell, P. B., Quinn, P., and Holben, B. N.: Geostationary satellite retrievals of aerosol optical thickness during ACE-Asia, J. Geophys. Res., 108, 1-14, 2003.

Wang, J. and Martin, S. T.: Satellite characterization of urban aerosols: Importance of including hygroscopicity and mixing state in the retrieval algorithms, J. Geophys. Res., 112, D17203, doi:10.1029/2006JD008078, 2007.

Yang, P. and Liou, K. N.: Geometric-optics-integral-equation method for light scattering by nonspherical ice crystals, Appl. Opt., 35, 6568-6584, 1996.

Yang, P., Feng, Q., Hong, G., Kattawar, G. W., Wiscombe, W. J., Mishchenko, M. I., Dubovik, O., Laszlo, I., and Sokolik, I. N.: Modeling of the scattering and radiative properties of nonspherical dust-like aerosols, J. Aerosol Sci., 38, 995-1014, 2007.

Yurkin, M. A. and Hoekstra, A. G.: User Manual for the Discrete Dipole Approximation Code ADDA v. 0.79, http://a-dda. googlecode.com/svn/tags/rel_0_79/doc/manual.pdf, 2009. 